\title{
Mallines en la Sierra de Comechingones, Sierras Pampeanas, Argentina. Caracterización geológico-geomorfológica y reconstrucción paleoambiental durante el Holoceno
}

\author{
M. Jimena Andreazzini ${ }^{1,2}$, Susana B. Degiovanni ${ }^{1}$, Aldo R. Prieto ${ }^{3}$, \\ Alfonsina Tripaldi', ${ }^{4}$, M. Elisa Luque ${ }^{6}$
}

\author{
${ }^{I}$ Departamento de Geología, Universidad Nacional de Río Cuarto, RN 36, km 601, X5804BYA, Río Cuarto, Córdoba, Argentina. \\ mandreazzini@exa.unrc.edu.ar; sdegiovanni@exa.unrc.edu.ar \\ 2 CONICET (Consejo Nacional de Investigaciones Cientificas y Técnicas), Godoy Cruz 2290 (C1425FQB) CABA, Argentina. \\ 3 IIMYC, Universidad Nacional de Mar del Plata, CONICET, FCEyN, Laboratorio de Paleoecología y Palinología, Funes 3250,7600 \\ Mar del Plata, Argentina. \\ aprieto@mdp.edu.ar \\ 4 Universidad de Buenos Aires, Facultad de Ciencias Exactas y Naturales, Departamento de Ciencias Geológicas, Intendente Güiraldes \\ 2160, Ciudad Universitaria, C1428EGA, Buenos Aires, Argentina. \\ alfotripaldi@gmail.com \\ 5 CONICET, Universidad de Buenos Aires, Instituto de Geociencias Básicas, Aplicadas y Ambientales de Buenos Aires (IGEBA), \\ Intendente Güiraldes 2160, Ciudad Universitaria, C1428EGA, Buenos Aires, Argentina. \\ ${ }^{6}$ Departamento de Ciencias Naturales, Universidad Nacional de Rio Cuarto, RN 36, Km 601, X5804BYA, Río Cuarto. Córdoba, \\ Argentina. \\ mluque@exa.unrc.edu.ar
}

\begin{abstract}
RESUMEN. Los mallines son humedales de alto valor ambiental y son frecuentes en diversas regiones de la Argentina, como la Patagonia, la Cordillera de los Andes y las Sierras Pampeanas. En particular en esta última región, los estudios sobre su funcionamiento y dinámica son aún insuficientes y parciales. En este trabajo, se analizan los factores geológicogeomorfológicos que influyeron en el origen, distribución, morfometría y dinámica de mallines del sector sur de la Sierra de Comechingones (Sierras Pampeanas de Córdoba, Argentina) y se realiza una reconstrucción paleoambiental a partir del registro sedimentológico, polínico y diatomológico de uno de estos sistemas durante el Holoceno. El área de estudio forma parte de una paleosuperficie de erosión desarrollada sobre rocas de basamento ígneo-metamórfico con anterioridad a la orogenia andina, la cual se preserva en el faldeo oriental de esta sierra y presenta distinto grado de incisión fluvial. El mayor desarrollo de los mallines se asocia a ambientes geomorfológicos con baja actividad morfodinámica, preferentemente sobre rocas graníticas, y depósitos loéssicos/loessoides. La fuente principal de los materiales que forman los depósitos de mallines es la removilización de las secuencias loéssicas/loessoides cuaternarias situadas en el sector serrano. Los registros sedimentológico, polínico y diatomológico sugieren la persistencia de estos ambientes en los sectores altos de las Sierras de Comechingones durante gran parte del Holoceno, con contracciones y expansiones como respuesta a la variabilidad ambiental. Las condiciones climáticas fueron variables, con un período más seco que el actual, al menos temporariamente, entre $c a$. 7.000 y 4.700 cal. años AP (6.400 y $4.100{ }^{14} \mathrm{C}$ años AP) y, a partir de $\operatorname{los} 4.700$ cal. años AP (4.326 ${ }^{14} \mathrm{C}$ años AP) se habrían establecido condiciones climáticas semejantes a las actuales. Los procesos de incisión e integración de las redes de drenaje que ocurrieron en las últimas centurias iniciaron la desactivación y pérdida de estos humedales, en especial a partir de la década de 1970, por el incremento en las precipitaciones y, subordinadamente, los frecuentes incendios forestales.
\end{abstract}




\begin{abstract}
Wet-meadows in the Comechingones Range, Pampean Ranges, Argentina. Geological-geomorphological characterization and paleoenvironmental reconstruction during the Holocene. Wet-meadows are wetlands of high environmental value and common in the Patagonia, Cordillera de los Andes and Pampean Ranges of Argentina. Particularly, the studies about the functioning and dynamics of wet-meadows are still insufficient and partials in Pampean Ranges. In this paper we analyze the geological-geomorphological factors that influenced the origin, distribution, morphometry and dynamics of wet-meadows in highlands of the southern Comechingones Range (Pampean Ranges of Córdoba, Argentina). A paleoenvironmental reconstruction from sedimentological, palynological, diatomological and chronological records of one of these systems is also proposed. The study area is located at an erosion paleosurface developed previously to the andean orogeny, on an igneous-metamorphic basement rocks. This paleosurface is preserved in the eastern slope of the Comechingones Range and shows different degree of fluvial incision. Most wet-meadows are linked to geomorphological environments with low morphodynamic activity, especially in the granitic rocks and loessic/loessoid deposits preserved in summit plains. The main source of sediments for wet-meadows is the reworking of Quaternary loessic/loessoide sequences. The wet-meadow paleorecords suggests the persistence of wetlands in the Comechingones Range highlands during most of the Holocene, with contractions and expansions in response to environmental variability. The Holocene climate conditions were variable, mainly related to changes in water availability and temperature. A drier period than the current, at least temporarily, took place between $c a .7,000$ and 4,700 cal. years BP $\left(6,400\right.$ and $4,100{ }^{14} \mathrm{C}$ years BP). Climatic conditions similar to the current ones were likely established since 4,700 cal. years $\mathrm{BP}\left(4,326{ }^{14} \mathrm{C}\right.$ years $\left.\mathrm{BP}\right)$. During the last centuries, incision and drainage networks integration processes, promote the removal of several wetlands, especially since 1,970 s due to precipitation increasing and, subordinately, frequent wildfires.
\end{abstract}

Keywords: Wetlands, Geology, Morphometry, Polen, Diatoms, Paleoenvironmental, Paleoclimate.

\section{Introducción}

Los humedales son áreas donde la saturación con agua del sustrato (al menos temporalmente durante el año) es el factor dominante que determina la naturaleza del desarrollo del suelo y de las comunidades de plantas y animales que viven en él y en su superficie (Cowardin et al., 1979). Estos ambientes han sido estudiados y clasificados tanto para regiones templadas y húmedas (Brinson y Malvárez, 2002; Manzano et al., 2002) como áridas (Tooth y McCarthy, 2007; Pigati et al., 2014). Particularmente, las vegas o mallines constituyen un tipo de humedal que es muy frecuente en diversas regiones de la Argentina como la Patagonia, la Cordillera de los Andes y las Sierras Pampeanas. Se desarrollan comúnmente donde una cuenca pequeña o fondo de valle localmente amplio se rellena con depósitos aluviales y coluviales de granulometría fina, de reducido espesor, como resultado de algún tipo de control estratigráfico, en el nivel de base o en el lecho rocoso (Stillwater Sciences, 2012). Su formación requiere un significativo suministro de agua, alguna forma de constricción del valle y la presencia de depósitos de grano fino que retarden la circulación del agua subterránea (Lord et al., 2011). La vegetación en estos ambientes es herbácea e hidrofítica formada por gramíneas y ciperáceas que forman molisoles, suelos minerales con abundante materia orgánica (Roig y Roig, 2004). En determinadas circunstancias ambientales la vegetación puede dar lugar a la formación de una capa de turba, histosoles, interpretándose en ese caso como turbales. Mazzoni y Rabassa (2013) observaron en los mallines de la Patagonia una alta variabilidad en la distribución de la vegetación, en función de la presencia y permanencia del agua, tanto en superficie como en profundidad. Por otro lado, Méndez (2007) identificó dos grupos de vegas en los Andes Centrales de Mendoza, basándose en diferencias de la vegetación en función de la altitud.

A pesar de su baja representatividad en superficie, los mallines constituyen sistemas de alto valor ambiental, no sólo por su interés como recurso productivo (fuente de agua y alimento para la ganadería y el consumo humano) sino también por sus funciones ecológicas. Los mallines actúan en la regulación hídrica manteniendo el agua excedente de la estación húmeda, regulan los caudales de los arroyos mitigando crecidas súbitas durante las tormentas, y actúan como filtro y retención de sedimentos. Además, tienen un rol importante en el secuestro de carbono debido al alto contenido de materia orgánica de sus suelos, sustentan una alta diversidad biológica especializada (especies hidrófitas y halófitas), proveen de hábitat y/o alimentos a una amplia variedad de especies de fauna silvestre y tienen un rol destacado en el reciclado de nutrientes (Gaitán et al., 2015).

Las causas más frecuentes que conducen a la degradación de estos ambientes son el sobrepastoreo (Utrilla et al., 2005) y la incisión de la red de drenaje 
(Lord et al., 2011, Scopel et al., 2017). Este último proceso provoca el descenso del nivel freático, causa cambios en la vegetación, altera la circulación del agua subterránea, y en casos extremos, la pérdida permanente de los mallines (Lord et al., 2011). La respuesta del nivel freático varía en función del tipo (difusa, fisuras) y la magnitud de la recarga del acuífero, las características litoestratigráficas (tipo, geometría, continuidad, potencia) y la conductividad hidráulica de los materiales que lo componen y la relación agua subterránea/sistemas superficiales. Las características geomorfológicas e hidrológicas de los mallines son muy variadas y, por lo tanto, su manejo y restauración requiere estudios de detalle, especialmente los relacionados a la conectividad entre el acuífero y los canales fluviales (Lord et al., 2011) En este sentido, diversos complejos de mallines han sido objeto de estudio con el fin de contribuir al manejo y la recuperación de estos ecosistemas (Chambers y Miller, 2004, 2011; Stillwater Sciences, 2012).

Por otra parte, y considerando las características que poseen los humedales en general, como ambientes receptores de agua y sedimentos, el estudio sedimentológico y del registro biológico preservado en ellos (e.g., polen o diatomeas) permite inferir condiciones paleoambientales y paleoclimáticas, especialmente durante el Cuaternario (e.g., Quade et al., 1995; Pigatti et al., 2010, 2014; Ashley et al., 2004; Owen et al., 2004; Hudson et al., 2016).

La mayoría de los estudios sobre mallines en la Argentina se han realizado en las regiones patagónica $\mathrm{y}$ andina. En esos trabajos se analizaron los aspectos edáficos, sedimentológicos, geomorfológicos e hídricos (Iriondo et al., 1974; Raffaele, 1999; Gandullo y Schmid, 2001; Utrilla et al., 2005; Mazzoni y Rabassa, 2013, Vázquez et al., 2013; Gaitán et al., 2015), se realizaron clasificaciones a partir de mapeos y procesamiento de imágenes satelitales (Gaitán et al., 2015) y estudios polínicos fósiles (e.g., Markgraf, 1983; Markgraf y Bianchi, 1999; Mancini, 2009; Bamonte y Mancini, 2011) y de la distribución de las comunidades vegetales (Gandullo y Schmid, 2001; Mazzoni y Rabassa, 2013; Vázquez et al., 2013). En cambio, para la región central de la Argentina y, en particular para las Sierras Pampeanas, las investigaciones de estos ambientes son escasas. Scopel et al. (2017) efectuaron una caracterización ecológica-ambiental de los humedales de las Sierras de Córdoba y San Luis. Krapovickas y Tauber (2016) realizaron un análisis del registro estratigráfico e interpretaciones paleoambientales de las pampas de altura de las Sierras Pampeanas de Córdoba, donde mencionan la existencia de condiciones de anegamiento temporario en el registro, pero no hacen referencia a la existencia de mallines. En la Sierra de Comechingones, González (2002) analizó las características edáficas de los mallines y Andreazzini et al. (2017a) reconstruyeron las condiciones paleoclimáticas y paleoambientales para el Holoceno en sucesiones de áreas cuspidales de las Sierras de Comechingones.

Las hipótesis de este trabajo fueron que la litología, geomorfología, y condiciones ambientales condicionan el origen, localización y dimensiones de los mallines, y que el registro sedimentológico y biológico de los mismos permite realizar reconstrucciones paleoambientales y paleoclimáticas. En este contexto los objetivos de este trabajo son: 1) analizar los factores geológico-geomorfológicos que influyen en la distribución y morfometría de mallines ubicados en el sector sur de la Sierra de Comechingones (Córdoba), entre los $32^{\circ} 42^{\prime}$ y $32^{\circ} 46^{\prime} \mathrm{S}$, y los $64^{\circ} 46^{\prime}$ y $64^{\circ} 57^{\prime} \mathrm{O}$, 2) estudiar la evolución paleoambiental de un mallín ubicado en el ambiente granítico a partir del registro sedimentológico y biológico (polen y diatomeas) de una sucesión sedimentaria representativa, y 3) efectuar inferencias paleoambientales para la región serrana y periserrana de este sector de Sierras Pampeanas, en especial para el Holoceno.

\section{Características del área de estudio}

\subsection{Contexto geológico}

La Sierra de Comechingones constituye el extremo meridional de las Sierras Grandes (Provincia Geológica de Sierras Pampeanas), tiene una longitud aproximada de $150 \mathrm{~km}$ (Fig. 1). Su elevación decrece hacia el sur, desde 2.884 m s.n.m. (Cerro Champaquí) a 650 m s.n.m. en sus afloramientos terminales. Presenta una típica sección transversal asimétrica; la escarpa de falla de su vertiente occidental tiene un gradiente pronunciado, con desplazamientos variables entre 200 y $1.000 \mathrm{~m}$, mientras la pendiente estructural de su borde oriental es más suave, mostrando escalones bien definidos, los cuales se han asociado con procesos tectónicos y/o erosivos. La pendiente oriental presenta alta disección fluvial con posterioridad a los movimientos andinos y conserva en sus partes cumbrales relictos de paleosuperficies de erosión (e.g., Jordan et al., 1989; 


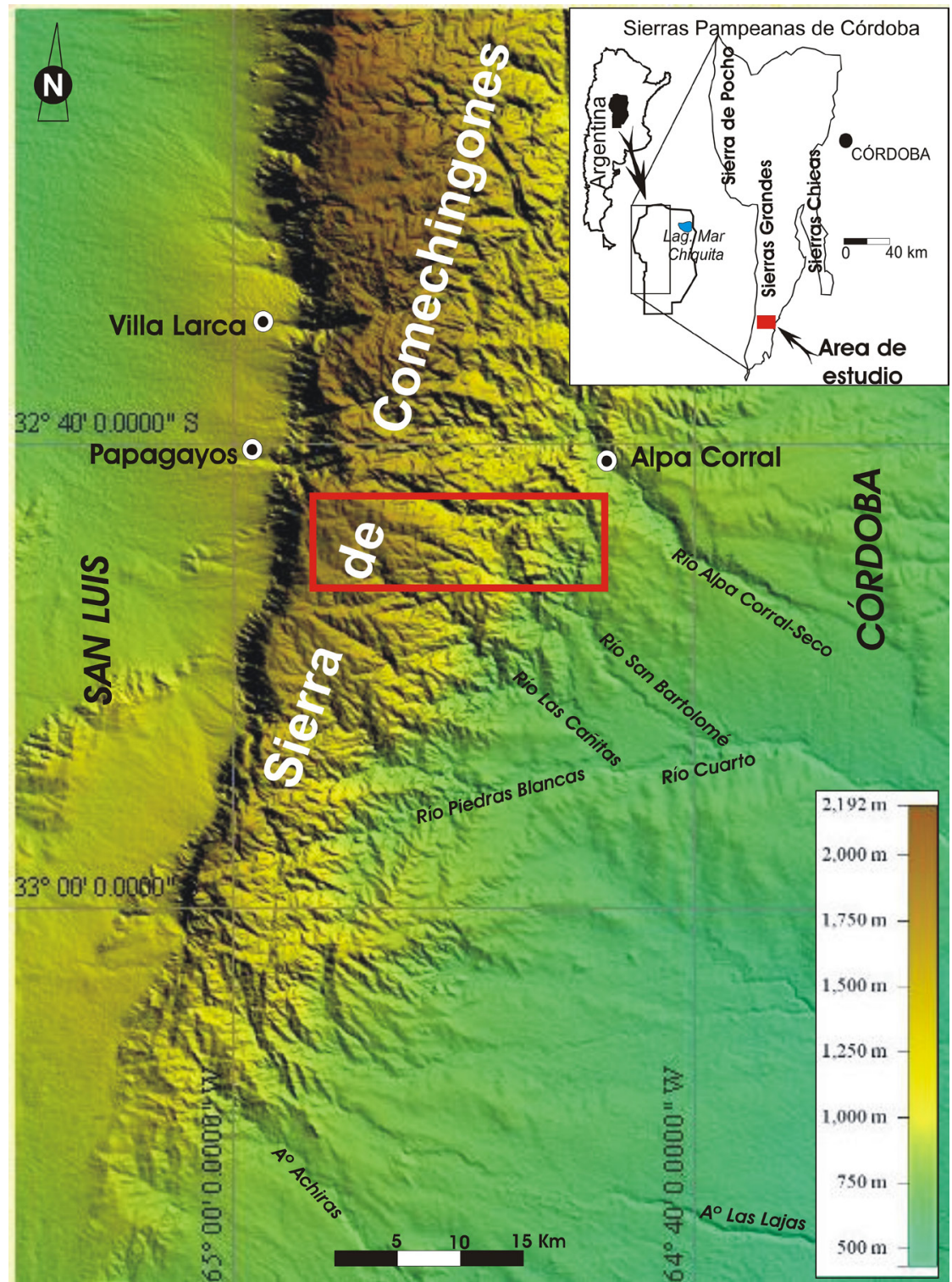

FIG. 1. Modelo de elevación digital del SRTM (Shuttle Radar Topography Mission), 90 m de resolución, del sector sur de la Sierra de Comechingones y localización del área de estudio (rectángulo rojo).

Carignano et al., 1999, 2014; Costa et al., 1999; Rabassa et al., 2010; Andreazzini y Degiovanni, 2014).

Las litologías dominantes en el área de estudio son rocas gneísico-migmatíticas (Complejo Monte Guazú), milonitas y ultramilonitas (Faja de Cizalla Guacha Corral) y rocas graníticas (batolito Cerro Áspero) (Fig. 2, sectores Ay B) (Fagiano, 2007; Rey Ripoll, 2008; Coniglio et al., 2010). El plutón Alpa Corral (localizado al sur, dentro del batolito Cerro
Áspero) muestra una zonación concéntrica, formada por una facies interna (aproximadamente el 93\% de los afloramientos), que corresponde a un granito biotítico grueso a porfirítico y una facies externa, constituida por un leucogranito inequigranular. Esta última presenta un mayor resalto topográfico debido al alto porcentaje de cuarzo de estas rocas (Pinotti et al., 2002, 2014). Todo el sector serrano está fuertemente afectado por estructuras frágiles 


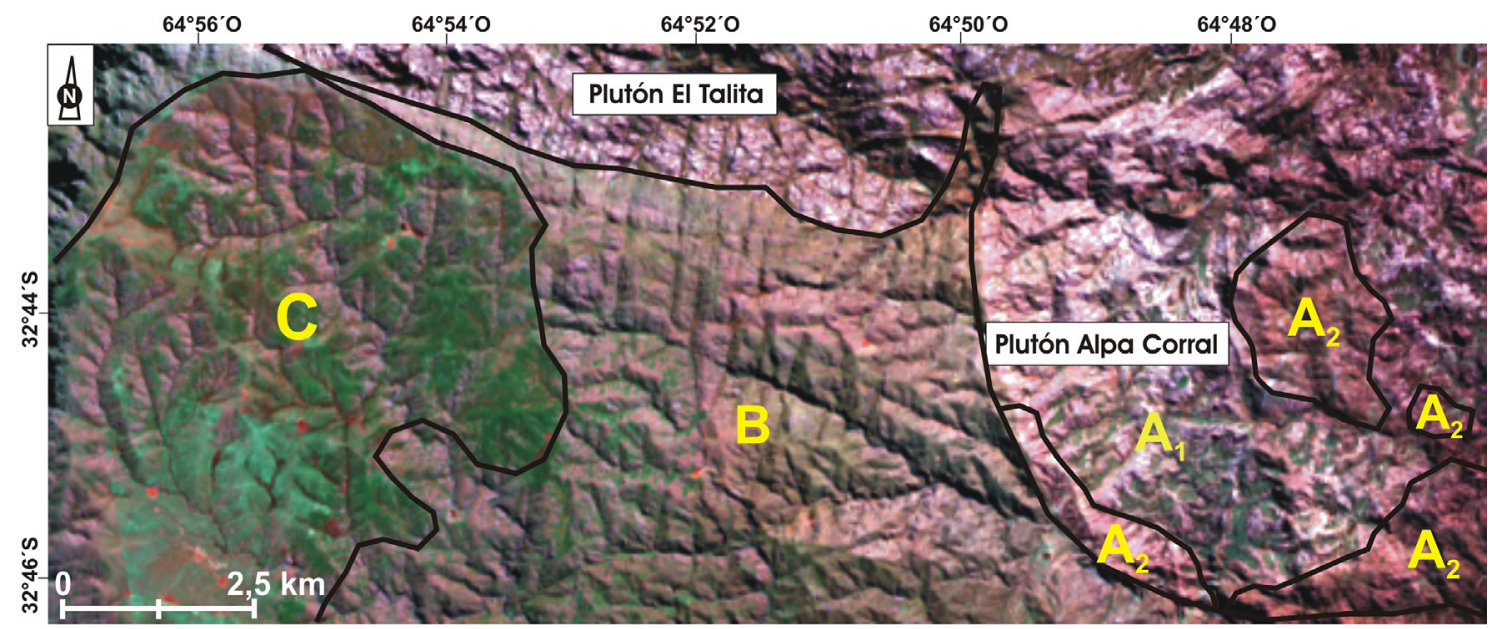

FIG. 2. Imagen satelital Landsat del área de estudio donde se diferencian las rocas graníticas del batolito Cerro Áspero (facies interna $\mathbf{A}_{1}$ y facies externa $\mathbf{A}_{2}$ ), las rocas gnéissico-migmáticas y milonítitas (B), y el basamento metamórfico con cubierta loéssica/ loessoide (pampa de altura) (C).

de distinta magnitud, principalmente de rumbos noroeste-sureste, suroeste-noreste y norte-sur.

Las rocas metamórficas, de moderado a alto grado, en facies de anfibolita en transición a facies de granulitas, presentan en general menor meteorización que las rocas graníticas, especialmente dentro de estas últimas aquellas facies de mayor tamaño de grano, y mayor grado de fracturamiento. Las milonitas y ultramilonitas por su parte, presentan un grado de meteorización variable, siendo localmente importantes los procesos de argilitización.

Los depósitos sedimentarios del Cuaternario cubren el sector pedemontano, los valles serranos y las planicies cumbrales. Los depósitos con mayor distribución y espesor se ubican en el piedemonte, representados por secuencias aluviales y coluviales de granulometría variada y sedimentos eólicos, parcialmente re-transportados como flujos hiperconcentrados (Kröhling y Carignano, 2014; Andreazzini, 2015; Krapovickas y Tauber, 2016). En los valles serranos dominan depósitos coluviales de espesor limitado. En los sectores de paleosuperficies cumbrales (pampas de altura) son frecuentes los sedimentos de origen loéssico/loessoide (Fig. 2, sector C), con un espesor que, en general, no supera los $5 \mathrm{~m}$, depositados durante el Último Máximo Glacial, y otros areno-gravosos producto de removilizaciones (escorrentía, procesos gravitatorios) locales durante el Holoceno (Andreazzini et al., 2013, 2017a; Krapovickas y Tauber, 2016). Estas sucesiones sedimentarias cuaternarias del ambiente serrano presentan niveles de paleosuelos de moderado a alto desarrollo (Manzur, 1997; Andreazzini et al., 2013, 2017a; Krapovickas y Tauber, 2016; Krapovickas et al., 2017).

En el paisaje serrano (pendientes, fondo de valles, depresiones en paleosuperficies cumbrales) se reconocen numerosos mallines. Ejemplos de estos ambientes en la Sierra de Comechingones fueron descriptos en la cuenca del río La Tapa (subcuenca del río Las Cañitas, Fig. 1, González, 2002) y en pampas de altura de la cuenca del río las Cañitas (Andreazzini et al., 2017a). González (2002) describió mallines entre los 700 y 1.800 m s.n.m., en posiciones bajas de los valles y laderas ( 4 a $8 \%$ de pendiente), formados por sedimentos de origen fluvial-coluvial, de textura franco-arcillosa, con alto contenido de materia orgánica (16-18\%), y suelos profundos. Por su parte los niveles limo-arenosos muy finos, con alto contenido de materia orgánica, y presencia de diatomeas, descriptos por Andreazzini et al. (2017a), corresponderían a ambientes de mallín desarrollados en fondo de valles.

\subsection{Clima e hidrología}

El clima de la región es templado subhúmedo, con una precipitación promedio anual de $909 \mathrm{~mm}$ en el sector serrano oriental-pedemontano (serie Las Tapias-Los Chañares, 1939-2014, Andreazzini, 2015), 
de la cual aproximadamente el $80 \%$ se concentra en primavera y verano con una marcada alternancia de períodos húmedos y secos. Particularmente, para el sector de las pampas de altura, se han registrado temperaturas máximas y mínimas absoluta de $31,3^{\circ} \mathrm{C}$ y $-9,6{ }^{\circ} \mathrm{C}$, respectivamente (serie La Cumbre, 2011-2016, Andreazzini, 2015). Las temperaturas mínimas por debajo de $0{ }^{\circ} \mathrm{C}$ son frecuentes durante los meses de invierno, donde se registran también algunas precipitaciones nivales. Estas condiciones producen congelamiento del agua en los mallines, en los cursos menores y, en algunos casos, de la parte superior de los suelos (Andreazzini, 2015). Las principales variables climáticas en las sierras difieren sustancialmente de aquellas registradas en las regiones extraserranas adyacentes (Capitanelli, 1979; Blarasin, 2003; Gorgas et al., 2003), siendo más húmedas las zonas serranas.

La sierra de Comechingones constituye una zona receptora de precipitaciones de vital importancia para el funcionamiento hidrológico regional. Los ríos y arroyos que la drenan son permanentes y algunos de ellos se infiltran al salir de la sierra alimentando los acuíferos de piedemonte y llanuras onduladas cercanas, con aguas de muy baja salinidad $(<0,5 \mathrm{gr} / \mathrm{L})$. En particular, la cuenca del Río Cuarto (donde se localiza el área de estudio), es exorreica, con pendiente atlántica, integrándose a la cuenca del Río de La Plata a través del sistema Saladillo-Carcarañá-Paraná.

En la zona serrana existe un acuífero en rocas fracturadas, con una permeabilidad secundaria en general baja, con pobre capacidad para conducir el fluido. En la Sierra de Comechingones, Blarasin et al. (2014) informan caudales erogados del orden de $5 \mathrm{~m}^{3} / \mathrm{h}$, para perforaciones en roca de aproximadamente $50 \mathrm{~m}$ de profundidad. El agua circulante en las rocas contribuye a los entornos clásticos presentes en los valles y da lugar a manantiales, permanentes o temporarios, de escaso caudal.

El acuífero en medio clástico está constituido por los sedimentos fundamentalmente cuaternarios que rellenan los valles intermontanos, y se alimenta de precipitaciones locales y del aporte de agua de las rocas circundantes (conductividad hidráulica 1-50 m/día). Las perforaciones existentes tienen rendimientos variados $\left(5-150 \mathrm{~m}^{3} / \mathrm{h}\right)$ (Blarasin et al., 2014).

Finalmente, los acuíferos en las pampas de altura son de escasa significación areal y poco espesor saturado. En general están compuestos por sedimentos arenosos muy finos-limosos de baja conductividad hidráulica (1-2 m/día), no tienen relevancia económica directa, pero actúan como zonas plenas de recarga aportando a arroyos colectores (Blarasin et al., 2014).

\subsection{Vegetación}

La vegetación del área pertenece al extremo sur del Distrito Chaqueño Serrano, Provincia Chaqueña y está representada por el bosque caducifolio xerófito con estratos de poáceas, cactáceas y bromeliáceas (Cabrera, 1976; Oggero y Arana, 2012), aunque las comunidades de pastizales de altura situadas a $>1.700 \mathrm{~m}$ s.n.m. han sido relacionadas con la vegetación andina y patagónica (Martínez et al., 2016). La zona de estudio está caracterizada principalmente por cuatro unidades de vegetación: la Estepa herbácea ("pastizal de altura"), el Bosque, la Pradera con una extensión areal reducida y en sectores puntuales la Estepa arbustiva ("romerillal") (Suárez y Vischi, 1997) (Fig. 3). Estas unidades se intercalan en su distribución y constituyen una matriz heterogénea del paisaje serrano que no se corresponden con los "pisos de vegetación" propuestos por Luti et al. (1979) para las sierras de Córdoba (Suárez y Vischi, 1997). Los contactos entre las comunidades de pastizales con las de Bosque son complejos (Cabido et al., 1996) y en la mayoría de los sectores los pastizales constituyen el contacto con el sector superior del Bosque (Giorgis et al., 2013). El mayor número de especies representadas pertenecen a las familias Poaceae, Asteraceae y Fabaceae (Oggero y Arana, 2012). Los cambios en la distribución de la vegetación se asocian con la heterogeneidad ambiental producida por la altitud, el tipo de suelo controlado por el sustrato litológico, las características geomorfológicas y climáticas (Suárez y Vischi, 1997), aunque la variabilidad en las comunidades actuales de los pastizales depende también de factores antrópicos (e.g., Giorgis et al., 2013). La constricción ambiental más importante de los pastizales es la baja temperatura (Díaz y Cabido, 1997) la que disminuye con la altura, mientras se incrementa la precipitación y el contenido de humedad en los suelos.

La Estepa herbácea se desarrolla en amplias superficies de manera continua por encima de los 800 m s.n.m. y está caracterizada por pastizales de herbáceas graminoides representadas por numerosos géneros de Poaceae y Cyperaceae. Se encuentran algunas especies arbustivas bajas como Baccharis articulata (Lam.) Pers. (Asteraceae), Cestrum parqui 


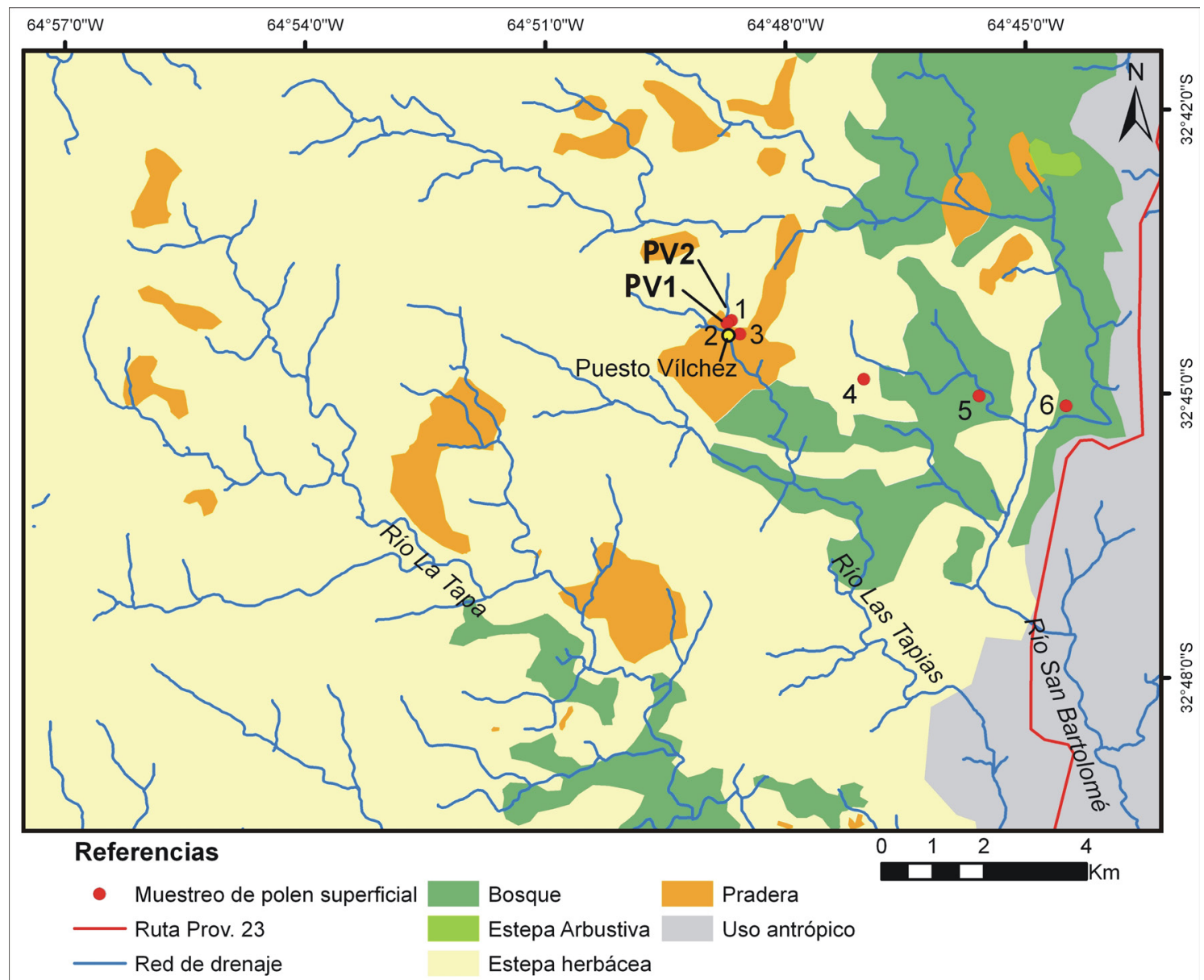

FIG. 3. Mapa de vegetación de la zona de estudio (modificado de Suárez, 1993 y Suárez y Vischi, 1997). Ubicación de las muestras polínicas superficiales y de los perfiles sedimentológicos estudiados en el mallín Puesto Vílchez (PV1 y PV2).

L' Hér. y Solanum sp.(Solanaceae). Por encima de los 900 m s.n.m. esta unidad aparece en forma dispersa y discontinua sobre los suelos desarrollados a partir del sustrato granítico (Suárez y Vischi, 1997) y metamórfico (Cantero et al., 2001) y por encima de los 1.700 m s.n.m. se desarrolla en las pampas de altura.

La Pradera, sin límite altitudinal, se desarrolla en áreas deprimidas con suelo incipiente y alta humedad donde se encuentran los mallines. La vegetación está caracterizada por pastizales con especies graminoides bajas, adaptadas a las condiciones de inundación, entre las que se encuentran Paspalum notatum Flüggé y Polypogon elongatus Kunth (Poaceae), Eleocharis sp.(Cyperaceae) y en los sectores encharcados aparecen Hydrocotyle sp., Typha dominguensis Pers. y Myriophyllum aquaticum (Vell.) Verc. (Oggero y Arana, 2012). Si bien esta unidad es la que reúne las condiciones de mayor humedad y encharcamiento, los mallines no son exclusivos de esta unidad sino que se localizan también en la Estepa herbácea. Ocasionalmente y en forma dispersa, tanto en la Pradera como en la Estepa herbácea, se encuentran especies arbóreas como Celtis sp., Schinus sp., Lithraea molleoides (Vell.) Engl. y Zanthoxylum coco Gillies ex Hook. f. \& Arn., además de numerosas herbáceas de la familia Asteraceae.

El Bosque (entre 700 y 1.100 m s.n.m.) se caracteriza por la predominancia de árboles como Celtis sp., L. molleoides, Schinus sp., Acacia caven (Molina) Molina, Z. coco, arbustos como B. articulata y Heterothalamus alienus (Spreng.) Kuntze (Asteraceae), 
C. parqui, Lippia sp. y Aloysia gratissima (Gill. et Hook) Tronc. (Verbenaceae), Colletia spinossisima J.F. Gmel. y Condalia microphylla Cav. (Rhamnaceae), Ligaria sp. y Tripodanthus sp. (Loranthaceae) y Ephedra spp. y varias hierbas (Oggero y Arana, 2012).

La Estepa arbustiva se ubica en zonas rocosas desde los 800 a los 950 m s.n.m. y se distribuye en forma discontinua ocupando extensiones reducidas en el norte de la zona de estudio (Fig. 3). En ella predominan los "romerillos", especies arbustivas de Asteraceae subf. Asteroideae como H. alienus, Acanthostyles buniifolius (Hook. \& Arn.) R.M. King \& H. Rob. y Baccharis spp. (Vischi et al., 1999). Estos autores no la mencionan para el sur del área de estudio, posiblemente por la escala de mapeo utilizada, sin embargo ha sido reconocida en los relevamientos florísticos realizados.

Es importante en el área la presencia de una gran variedad de helechos (Oggero y Arana, 2012). En las proximidades de los asentamientos rurales existen plantaciones de árboles introducidos como Gleditsia triacanthos L., Cupressus sp., Ulmus sp., Cedrus sp. y Pinus sp. La circulación y el asentamiento del ganado generan un constante disturbio sobre el suelo y la vegetación de los mallines en la Pradera y la Estepa herbácea donde aparecen algunas especies exóticas de Amaranthus-Chenopodioideae y Brassicaceae.

\section{Metodología de trabajo}

La realización del presente trabajo incluyó estudios geomorfológicos, sedimentológicos y paleoambientales. El trabajo de campo incluyó un análisis morfológico del paisaje, la observación y relevamiento de procesos geomorfológicos activos, el muestreo de muestras polínicas de superficie y la descripción y muestreo sedimentológico, polínico y de diatomeas. Los depósitos de mallines fueron muestreados en sucesiones expuestas por la incisión de arroyos donde se realizaron descripciones sedimentológicas y se recolectaron muestras para estudios sedimentológicos y paleoambientales. La utilización de muestreadores tipo vibracoring y ruso para la extracción de testigos de los mallines activos no fue posible debido a que estos depósitos tienen intercalaciones de granulometría gravosas que imposibilitaron la penetración del instrumental. En esta primera etapa se seleccionaron, en el ambiente granítico, dos sucesiones expuestas representativas del área en inmediaciones del Puesto Vílchez (PV1 y PV2; Fig. 3).

\subsection{Análisis geomorfológicos}

El reconocimiento geomorfológico se realizó mediante teledetección y empleando imágenes satelitales Google Earth y Bing, de un área representativa del sector sur de la Sierra de Comechingones entre los $32^{\circ} 42^{\prime} \mathrm{S}$ y $32^{\circ} 46^{\prime} \mathrm{S}$ y $64^{\circ} 46^{\prime} \mathrm{O}$ y $64^{\circ} 57^{\prime} \mathrm{O}$ (Fig. 1). Se definieron unidades geomorfológicas y en cada una se identificaron 30 sitios ocupados por mallines, caracterizando luego el contexto litológico-geomorfológico, su posición en el paisaje y la relación con la red de drenaje de cada uno de ellos. Se determinaron la forma y dimensiones en superficie de los mallines y se realizó el tratamiento estadístico descriptivo de datos cuantitativos (ancho, longitud, pendiente) y cualitativos (morfología en planta, posición dentro de la red de drenaje), para relacionar estos parámetros con las distintas unidades geomorfológicas.

A partir del análisis de hojas topográficas escala 1:50.000 del Instituto Geográfico Nacional de la Argentina (IGN) y de un modelo de elevación digital del terreno ALOS PALSAR de 12,5 m de resolución espacial se complementó la descripción geomorfológica y se definieron las redes de drenaje. Se obtuvieron mapas de pendientes, de sombreado del terreno (Hillshading) y de profundidad de incisión de la red de drenaje utilizando el modelo de elevación digital y el Sistema de Información Geográfica SAGA.

Mediante el uso de fotografías aéreas (años 1970 y 1989) e imágenes satelitales (2010), y relevamiento geomorfológico de campo (terrazas, paleocanales) se analizaron variaciones en la densidad de drenaje y procesos de incisión en el valle donde se localizan las sucesiones sedimentarias estudiadas.

\subsection{Análisis sedimentológicos}

En las secciones PV1 y PV2 se determinó textura, color (Tabla de Color de Munsell), estructuras sedimentarias, grado de compactación, grado de bioturbación, tipo de contactos entre las unidades sedimentarias. En el laboratorio las muestras de sedimentos se secaron a temperatura ambiente $\mathrm{y}$, posteriormente, se desagregaron mecánica y químicamente. La distribución por tamaño de partícula se obtuvo utilizando un contador láser de partículas Malvern (modelo Mastersizer Hydro 2000); luego se clasificó según la propuesta de Folk et al. (1970) y se procesaron estadísticamente según Folk y Ward (1957). Se determinó el contenido de carbono orgánico 
total (COT) por pérdida por ignición (Heiri et al., 2001), utilizando $7 \mathrm{~g}$ de muestra tamizada a $2 \mathrm{~mm}$.

\subsection{Cronología}

Dos dataciones radiocarbónicas convencionales y seis AMS, determinadas sobre sedimentos ricos en materia orgánica (Tabla 1) proporcionaron el control cronológico para las sucesiones PV1 y PV2 del mallín Puesto Vílchez. Las dataciones radiocarbónicas fueron calibradas con la curva del hemisferio sur, SHCal13 (Hogg et al., 2013) utilizando el programa Calib Rev. 7.1.0 (Stuiver et al., 2018). El modelo de edad-profundidad para el perfil PV1 fue construido con el programa Tilia versión 2.0.4 (Grimm, 2004).

\subsection{Análisis diatomológico}

En el perfil PV1 se realizó un análisis cuantitativo de diatomeas en tres muestras. El material se disolvió en agua, el conteo de los frústulos se realizó bajo una magnificación de 400x y la identificación de especies a 1000x utilizando un microscopio Zeiss estándar 16. La identificación y la información ecológica de las diatomeas se basó en Krammer y Lange Bertalot (1986, 1988, 1991, 2000, 2004); Lange Bertalot (2001); Kusber y Jahn (2002) y Metzeltin et al. (2005).

\subsection{Análisis polínico}

Para analizar la relación polen-vegetación actual en el área del Puesto Vílchez, se recolectaron y analizaron seis muestras de sedimento superficial a lo largo de un gradiente altitudinal (Fig. 3). Para el análisis polínico fósil se muestreó el perfil PV1 (Fig. 3) de $540 \mathrm{~cm}$ mediante cajas metálicas y espátulas y se realizó un análisis preliminar de 31 muestras.

Las muestras superficiales se secaron a $60{ }^{\circ} \mathrm{C}$ durante $24 \mathrm{~h}$, y se usaron submuestras de $5 \mathrm{~g}$ de sedimento seco para el procesamiento, mientras que para las muestras fósiles se seleccionaron submuestras de $2-20 \mathrm{~cm}^{3}$ de sedimento a intervalos predeterminados. Previo a la extracción polínica se agregaron a cada submuestra tres tabletas con esporas de Lycopodium como marcador para calcular la concentración polínica. Se siguieron técnicas de preparación palinológicas estándar para los procesamientos (Faegri e Iversen, 1989).

Para la identificación del polen y las esporas se utilizó la colección de referencia del Laboratorio de Paleoecología y Palinología de la Universidad Nacional de Mar del Plata y atlas y claves publicadas (Heusser, 1971; Markgraf y D'Antoni, 1978). Debido a la baja resolución taxonómica del polen de Asteraceae, fueron agrupados como Asteraceae subf. Asteroideae (incluye hierbas y arbustos) y Asteraceae subf. Cichoroideae. Otras "monocotiledóneas" incluye a varias especies de Iridaceae, Amaryllidaceae y Bromeliaceae (hierbas y epífitas). Cada taxón se expresó en porcentaje de la suma total de polen, de la cual fueron excluidos los tipos polínicos extra-regionales e indeterminados. En las muestras superficiales se excluyeron los tipos exóticos o que indican disturbio y Urticaceae por estar sobrerrepresentada. Cyperaceae y Amaranthus-

TABLA 1. DATOS RADIOCARBÓNICOS PARA LAS SECCIONES PV1 Y PV2 DEL MALLÍN PUESTO VÍLCHEZ.

\begin{tabular}{|c|c|c|c|c|c|c|}
\hline Perfiles & $\begin{array}{l}\text { Prof. } \\
(\mathrm{cm})\end{array}$ & $\begin{array}{l}\text { Edad }{ }^{14} \mathrm{C} \\
(\operatorname{años} \mathrm{AP})\end{array}$ & $\begin{array}{c}\text { Promedio ponderado } \\
\text { de edad calibrada }\end{array}$ & $\begin{array}{l}\text { cal. años AP } \\
(2 \sigma)\end{array}$ & Material datado & $\mathbf{N}^{0}$ Lab. \\
\hline \multirow[t]{7}{*}{ PV1 } & 50 & $1.990 \pm 80$ & 1.990 & $1.708-2.091$ & materia orgánica & LP-3096 \\
\hline & 100 & $3.335 \pm 29$ & 3.519 & $3.446-3.612$ & materia orgánica & D-AMS 023105 \\
\hline & 200 & $4.326 \pm 34$ & 4.852 & $4.816-4.967$ & materia orgánica & D-AMS 023106 \\
\hline & 284 & $5.624 \pm 29$ & 6.360 & $6.297-6.415$ & materia orgánica & D-AMS 023107 \\
\hline & 372 & $6.600 \pm 42$ & 7.467 & $7.417-7.568$ & materia orgánica & D-AMS 023108 \\
\hline & 450 & $7.060 \pm 110$ & 7.843 & $7.621-8.025$ & materia orgánica & LP-3106 \\
\hline & 467 & $7.429 \pm 38$ & 8.225 & $8.153-8.340$ & materia orgánica & D-AMS 023105 \\
\hline PV2 & 340 & $4.140 \pm 38$ & 4.684 & $4.825-4.568$ & materia orgánica & D-AMS 028441 \\
\hline
\end{tabular}

LP: Laboratorio de Tritio y Radiocarbono (LATYR), CIG-CONICET- Universidad Nacional de La Plata, Argentina.

D-AMS: Direct-AMS, EE.UU. 
Chenopodioideae fueron excluidas en las muestras actuales y fósiles porque representan situaciones locales relacionadas con las condiciones edáficas. Para obtener una buena representación de los taxones que tienen polinización entomófila como la mayoría de los árboles y arbustos, se contaron al menos 200 granos de polen, excluyendo a Poaceae y Cyperaceae en las muestras actuales de los pastizales y en las fósiles. Las sumas polínicas fósiles varían entre 560 y 1.082 granos. Los diagramas polínicos y la zonación del perfil polínico PV1 se realizaron con el programa Tilia versión 2.0.4 (Grimm, 2004).

\section{Resultados}

\subsection{Caracterización geomorfológica del área}

El área de estudio forma parte de una extensa superficie de erosión desarrollada con anterioridad a la orogenia andina (Carignano et al., 1999; Rabassa et al., 2010; Andreazzini y Degiovanni, 2014) que constituye la pendiente estructural oriental de la Sierra de Comechingones. La misma presenta distinto grado de incisión fluvial, en función de su localización dentro de las morfoestructuras mayores (megabloques) y de la litología presente. Se diferenciaron tres unidades geomorfológicas, y la caracterización de los mallines se realizó en relación a estas unidades (Fig. 4A).

\subsubsection{Paleosuperficie desarrollada sobre rocas metamórficas, con bajo grado de incisión fluvial}

Se caracteriza por un paisaje de pampas de altura, basculadas hacia el este y sur, con cotas máxima y mínima aproximadas de 1.850 y 1.600 m s.n.m. (Fig. 4A y B), respectivamente, siendo las pendientes de la paleosuperficie del orden del 2-3\% (Fig. 4C) y los desniveles locales inferiores a $10 \mathrm{~m}$. El relieve es muy homogéneo, los afloramientos rocosos están restringidos a los canales fluviales, y otorgan al paisaje un aspecto crestiforme de bajo relieve, controlado por la orientación de las estructuras del basamento metamórfico. Debido a la posición que ocupan estas pampas, en los sectores cumbrales de las sierras, se las considera superficies relícticas, que disminuyen su extensión areal a medida que la red de drenaje evoluciona por erosión retrocedente.

En el área de estudio esta paleosuperficie está labrada sobre las metamorfitas del complejo Monte Guazú, y muestra un bajo grado de incisión fluvial, en general inferior a los $20 \mathrm{~m}$ (Fig. 4D). Se presenta parcialmente cubierta por depósitos loéssicos y loessoides cuaternarios, de espesor variable, entre pocos centímetros hasta alrededor de $5 \mathrm{~m}$, que suavizan las formas del relieve, correlacionables con la Formación Vaca Corral (Krapovickas y Tauber, 2016) en otras pampas de altura de las Sierras de Córdoba. Sobre esta cubierta localmente se han desarrollado cárcavas (Fig. 5A).

Las márgenes de los surcos, cárcavas y cauces manifiestan procesos gravitatorios compuestos, desde deslizamientos (rotacionales dominantes) en las cabeceras hasta flujos en la base, generados por la saturación y posterior desplazamiento de los depósitos cuaternarios. Estos mecanismos llevan a la extensión, ensanchamiento y/o generación de cárcavas, observándose en muchos casos el basamento cristalino en la base de las mismas, que suele actuar como superficie de deslizamiento.

\subsubsection{Paleosuperficie desarrollada sobre rocas metamórficas, con alto grado de incisión fluvial}

Esta unidad está altamente disectada por cauces fluviales (Fig. 5B) y los remanentes de la paleosuperficie son muy reducidos y se asocian a las áreas de interfluvios. Se la reconoce entre los 1.700 y 900 m s.n.m. (Fig. 4A y B). Posee un paisaje mayormente homogéneo con múltiples afloramientos crestiformes de metamorfitas foliadas, dispuestos con rumbo submeridiano y buzamiento de bajo a medio ángulo hacia el este. La cubierta sedimentaria cuaternaria es inferior al metro, y se localiza en laderas y fondos de valle, en tanto que el porcentaje de afloramientos rocosos es variable, pudiendo alcanzar localmente un 50\%. Las pendientes de la paleosuperficie muestran valores de 5-6\% (Fig. 4C) y los desniveles internos máximos de este paisaje son del orden de $30-35 \mathrm{~m}$.

Los interfluvios están cubiertos por depósitos de talud (caídas de bloques, deslizamientos de rocas y detritos), de limitado espesor y heterogeneidad granulométrica. Los mismos se encuentran edafizados y estabilizados, exhibiendo mínimos rasgos erosivos (pequeñas cárcavas, en general estables).

La red de drenaje está muy controlada por los rasgos estructurales, especialmente los sistemas de fallas y fracturas noroeste-sureste y noreste-suroeste. Los cursos poseen un diseño de canal rectilíneo, perfiles longitudinales con numerosos quiebres (saltos-knickpoint) y alta pendiente (Fig. 4C). Los valles presentan forma de "V", son relativamente 


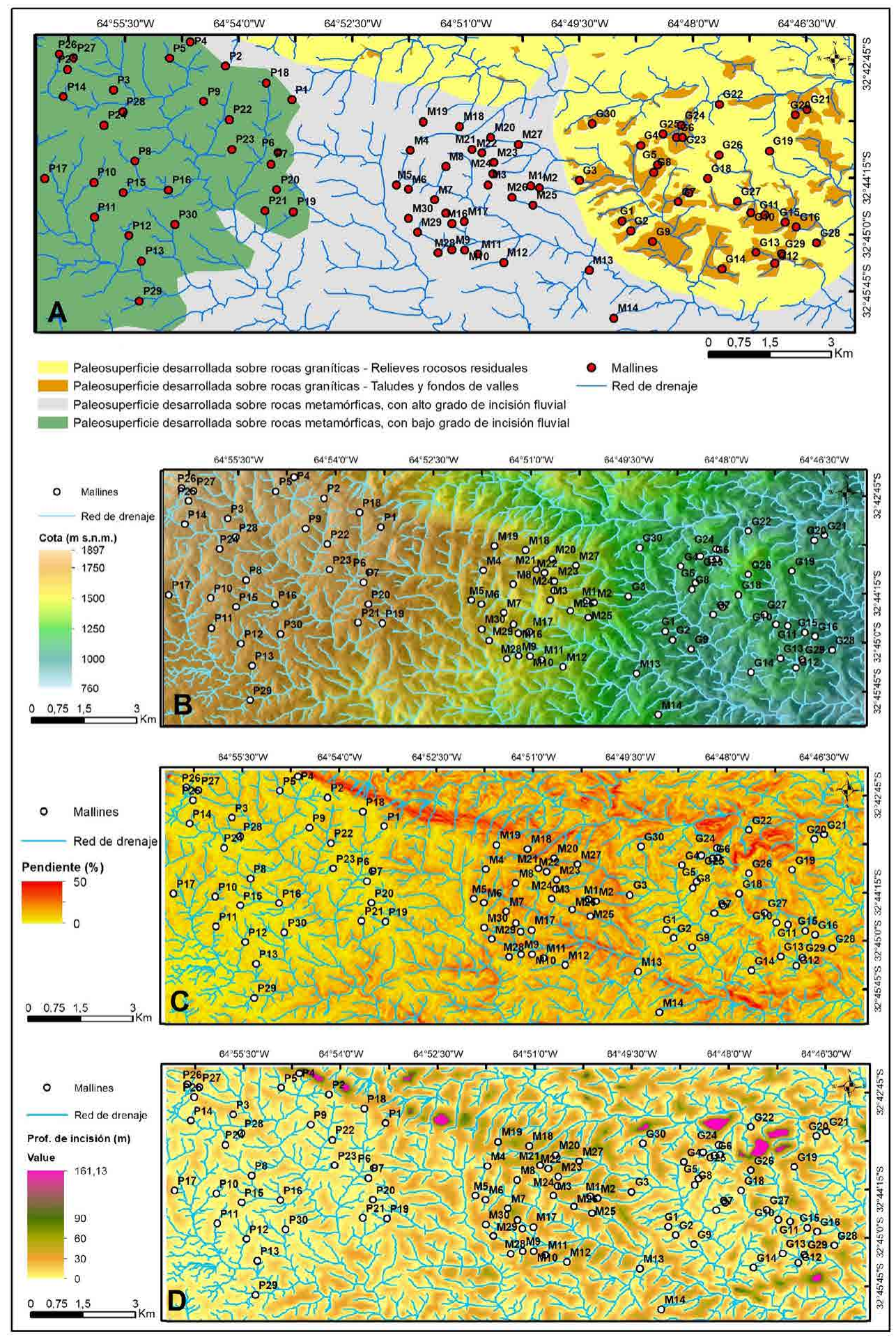

FIG. 4. A. Mapa geomorfológico del área de estudio y localización de los mallines estudiados. B. Modelo de elevación del terreno ALOS PALSAR, de $12.5 \mathrm{~m}$ de resolución combinado con un mapa de sombreado del terreno. C. Mapa de pendientes, derivado del modelo de elevación ALOS PALSAR. D. Mapa de profundidad de incisión de la red de drenaje, derivado del modelo de elevación ALOS PALSAR. 

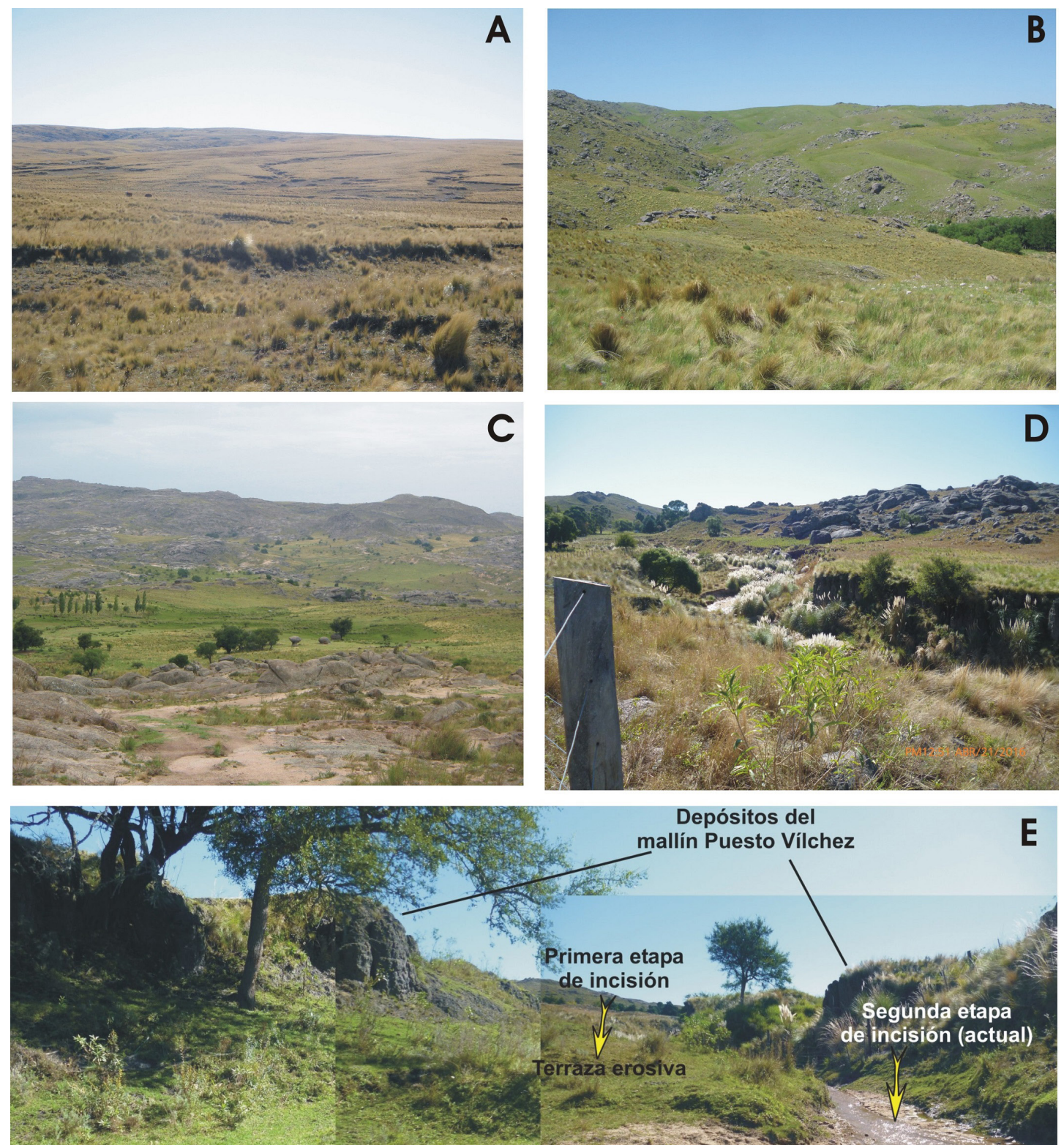

FIG. 5. Vistas del relieve en: A-B. Paleosuperficie metamórfica con bajo y alto grado de incisión fluvial, respectivamente. C. Relieves residuales y fondos de valle en la paleosuperficie granítica, en primer plano se observa meteorización de la roca. D. Afloramientos graníticos y depósitos aluviales/coluviales hacia el eje de un canal incidido. E. Pulsos de incisión en el mallín Puesto Vílchez.

cerrados e incididos, con profundidades del orden de 40-80 $\mathrm{m}$ en los colectores mayores (Fig. 4D).

\subsubsection{Paleosuperficie desarrollada sobre rocas graníticas}

La tercera unidad geomorfológica es una paleosuperficie desarrollada sobre rocas graníticas, donde se diferenciaron las subunidades denominadas Relieves rocosos residuales y Taludes y fondos de valle con cubierta aluvial/coluvial (Fig. 4A). Esta unidad se encuentra a una cota topográfica menor que los afloramientos de rocas metamórficas de las unidades precedentes; la unidad interna del plutón Alpa Corral se presenta entre los 900 y 1.050 m s.n.m. y 
alcanza los 1.200 m s.n.m. en la externa (Figs. 2 y 4B), presentando un escarpe erosivo del orden de $100 \mathrm{~m}$, el cual se aprecia más claramente en el contacto entre el plutón El Talita y la roca de caja (Figs. 2 y 4C). Los desniveles internos máximos en la unidad interna del granito (Fig. 4D) son de 20-25 m.

En los relieves rocosos residuales se reconocieron, principalmente, formas mesoscópicas (tafonis, bloques redondeados), asociadas a la facies de borde del plutón Alpa Corral, donde la roca presenta alto grado de diaclasamiento. Localmente se reconocieron formas graníticas de mayor tamaño como bornhardt y törs.

Los taludes presentan morfologías asociadas a procesos gravitatorios (flujos de detritos, caídas y deslizamientos de bloques), tales como taludes de transporte (zona proximal) y conos de detritos (zona distal) (Fig. 5C).

Las áreas negativas comprenden formas vinculadas a actividad fluvial y depresiones semi-cerradas asociadas a procesos de meteorización diferencial. Los cursos de agua principales están en etapa de incisión, presentan valles profundos y saltos de agua de varios metros de altura.

En los valles las pendientes decrecen de 14-18\% en los afloramientos graníticos de los bordes, a 8,5-7,5\% en los depósitos aluviales/coluviales hacia el eje del canal (Fig. 5D). La red de drenaje muestra un diseño angular-subdendrítico, evidenciando un alto control estructural, que para los cursos de mayor orden está dado por el sistema conjugado de fallas y fracturas nornoroeste-sursureste y noreste-suroeste. Actualmente, los procesos dominantes son la erosión hídrica (cárcavas) y la fluvial en fondos y márgenes de valles. En los colectores principales se identificaron diferentes pulsos de incisión (Fig. 5E).

En esta unidad se observaron numerosos sectores cubiertos por arenas formadas por meteorización de las rocas graníticas (Fig. 5C). A su vez, se reconocen depósitos coluviales, aluviales y de mallines (en algunos casos con alta participación de loess removilizado), en pendientes, depresiones cerradas $\mathrm{y}$ fondos de valle.

\subsection{Distribución y morfometría de los mallines}

El análisis de la morfometría de los mallines en relación con su posición en las distintas unidades geomorfológicas, permitió determinar varias características particulares para cada unidad.
En la Paleosuperficie desarrollada sobre rocas metamórficas, con bajo grado de incisión fluvial las dimensiones de los mallines son muy variables (de 60 a $880 \mathrm{~m}$ de largo, y de 8 a $100 \mathrm{~m}$ de ancho), con valores promedio de $280 \mathrm{~m}$ y $46 \mathrm{~m}$ en largo y ancho, respectivamente (Fig. 6) y pendientes que varían entre 2,8 y $8,5 \%$ (Fig. 7A). En relación a su posición en la red de drenaje, el 76,7\% se localizan en las zonas de cabeceras (Fig. 7B, e.g., P1, P2, P9, P15 en Fig. 8A y D), tanto en bajos de primer orden (el $65 \%$, e.g., P1, P4, P9 en Fig. 4 B y C) como en la confluencia de los mismos (el 35\%, e.g., P2, P10, P19, en Fig. 4 B y C). Estos poseen formas irregulares y subredondeadas (Fig. 7C), y no están incididos. El 23,3\% se localizan en fondos de valle de mayor orden (Fig. 7B y e.g., P8, P11, P16, Fig. 4 B y C), presentando dominantemente formas elongadas (Fig. 7C) y distinto grado de incisión por procesos de carcavamiento (e.g., P18, Fig. 8A). Se preservan en cabeceras o fondo de cárcavas poco profundas, donde los procesos de incisión no alcanzaron el basamento cristalino (Fig. 8B y C), mientras que aguas abajo de estos sitios los mallines están drenados o son inactivos. Considerando que en los procesos de integración de redes de drenaje se reconocen sucesivos tramos que incluyen frentes de retroceso (knickpoint), segmentos de conducción y zonas de descarga (Bull, 1997), estos mallines son discontinuos a lo largo de los ejes de los valles.

En la Paleosuperficie desarrollada sobre rocas metamórficas, con alto grado de incisión fluvial dominan los mallines con formas irregulares y alargadas (Fig. 7C), con una longitud y un ancho promedio de $148 \mathrm{~m}$ y $38 \mathrm{~m}$, respectivamente (Fig. 6) y pendiente promedio del $13 \%$. El $80 \%$ de los mallines se localizan en las zonas de cabeceras (Fig. 7B), tanto en líneas de escurrimiento ( $c a .71 \%$, e.g., M5, M19, M30, Fig. 4B y C) como en confluencias de ejes de primer orden (ca. 29\%, e.g., M6, M8, Fig. 4B y C, y M8, M18, M20, M24, Fig. 9A-C), pudiendo o no tener un pequeño canal que lo atraviesa. El 20\% restante se ubica en posiciones aledañas a los arroyos (e.g., M1, Fig. 9A).

En la Paleosuperficie desarrollada sobre rocas graniticas el $85 \%$ de los mallines se localizan en la facies interna del plutón Alpa Corral, dominando aquellos que geomorfológicamente ocupan los fondos de valles o áreas deprimidas o depresiones donde conforman pequeñas llanuras dentro de este ambiente (Figs. 4A y C, 7B y $10 \mathrm{~A}$ y $\mathrm{C}$, e.g., G5, G6 y G8). Tienen formas elongadas, con ancho 

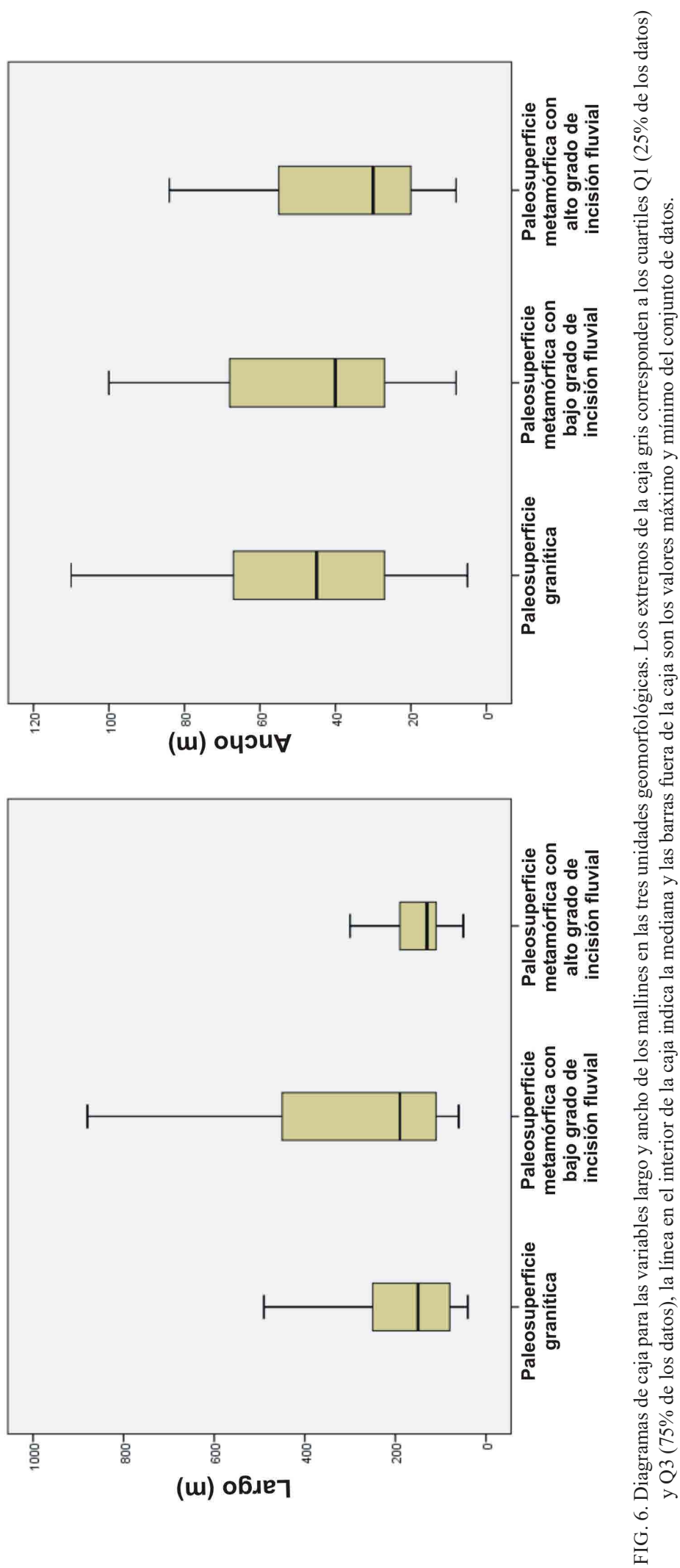

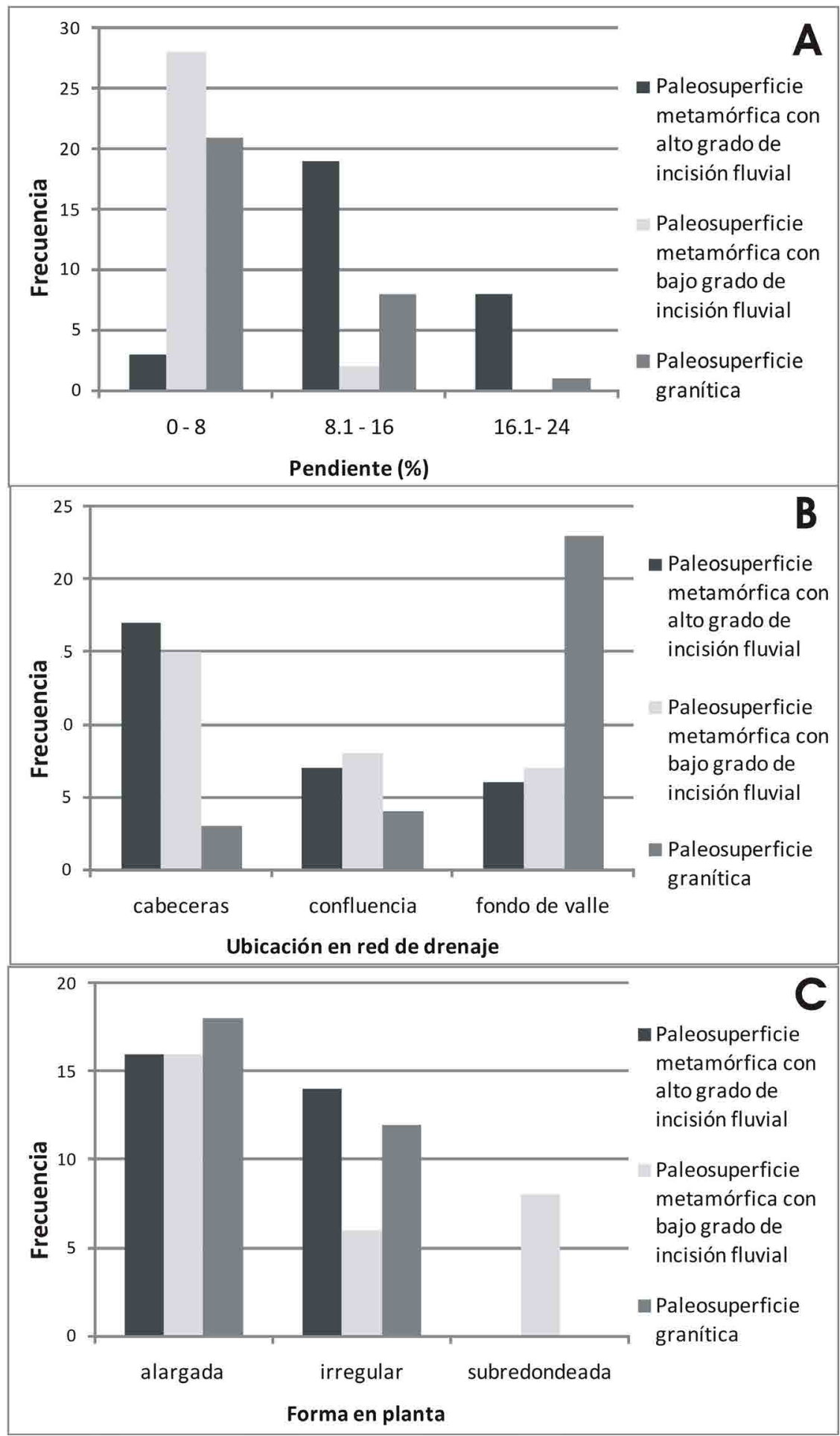

FIG. 7. Gráfico de frecuencias de: rango de pendientes (A), posiciones en la red de drenaje (B), y forma en planta de los mallines (C) en las tres unidades geomorfológicas. 


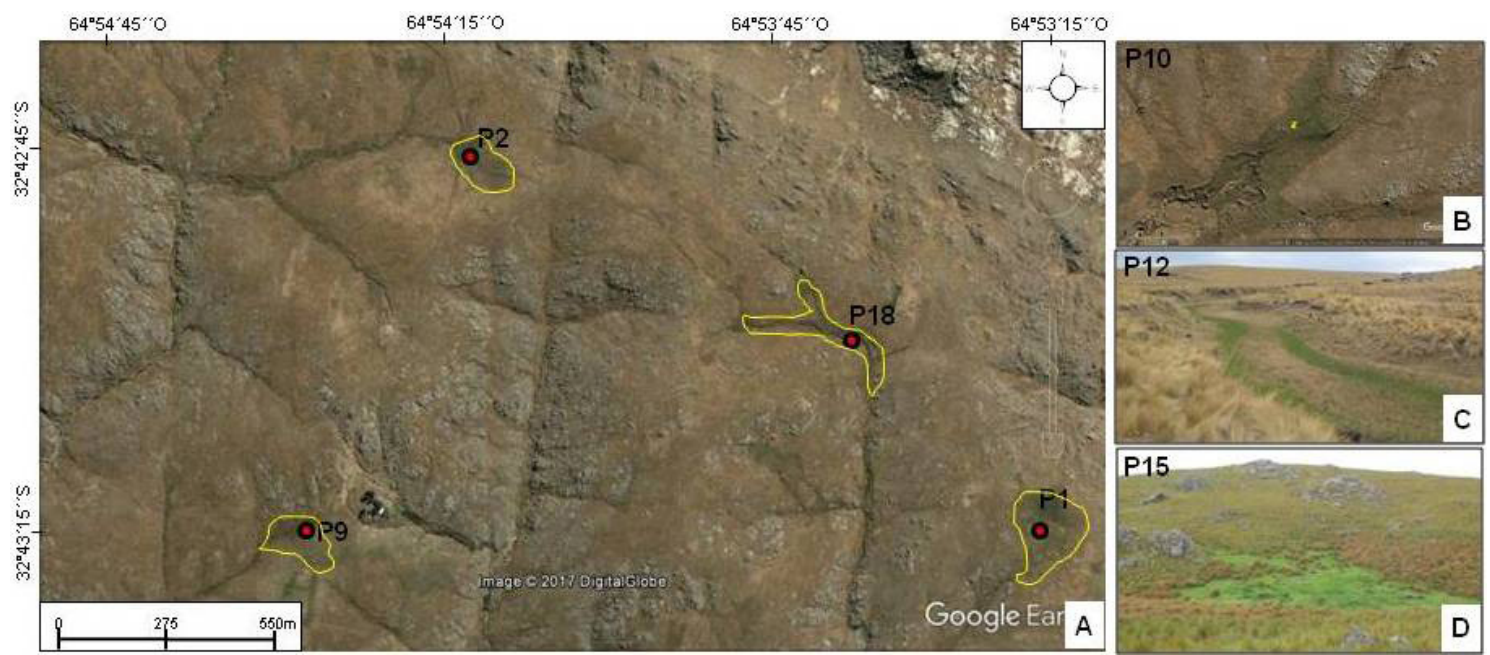

FIG. 8. A. Detalle de un sector de la paleosuperficie metamórfica con bajo grado de incisión fluvial (imagen satelital Google Earth). Con contornos amarillos se indican las áreas ocupadas por algunos de los mallines estudiados. B. Vista de detalle del mallín P10, donde se observa una cárcava en retroceso. C-D. Vistas de los mallines P12 y P15 (la ubicación de los tres últimos se encuentra en la figura 4).
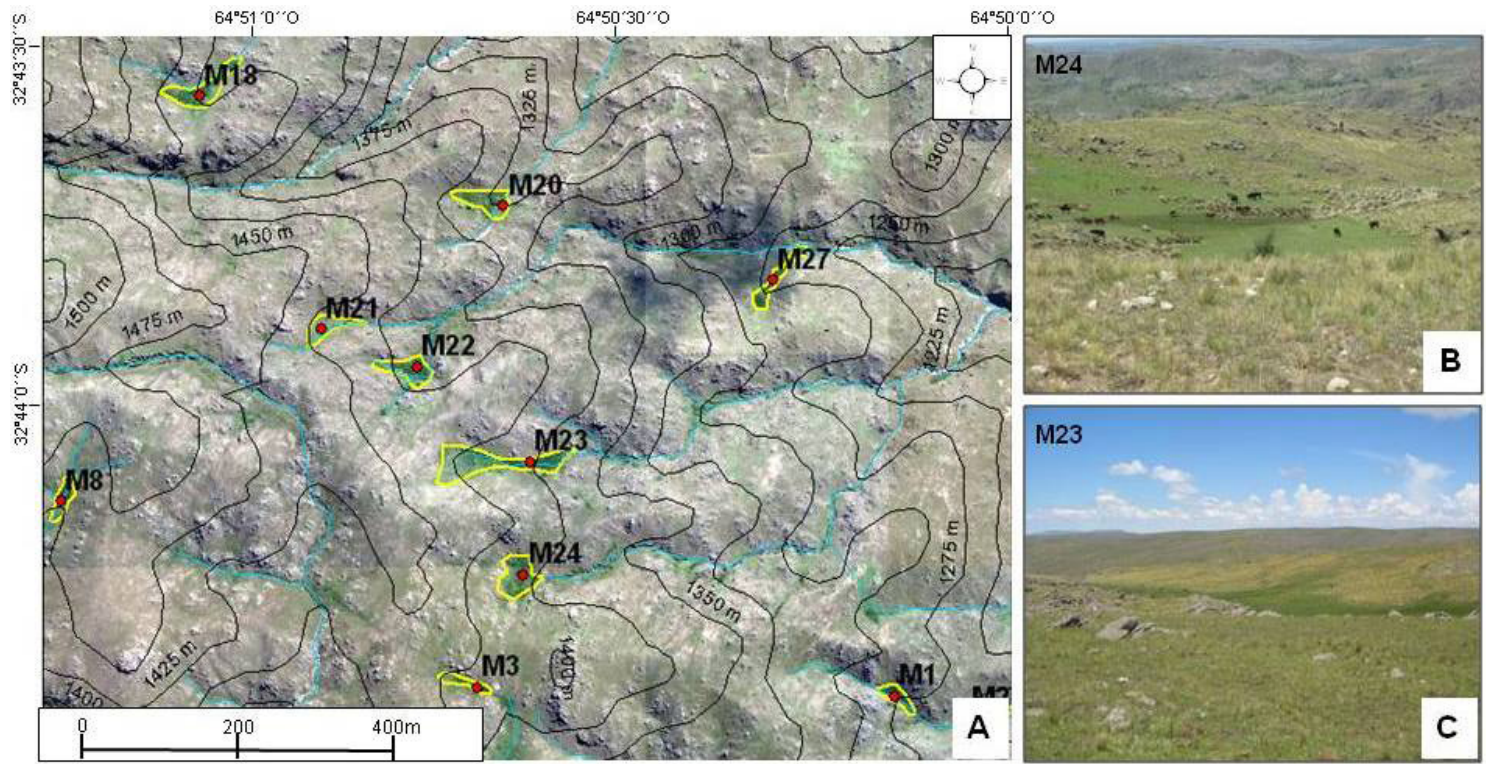

M23

FIG. 9. A. Detalle de un sector de la paleosuperficie metamórfica con alto grado de incisión fluvial (imagen satelital Bing). Con contornos amarillos se indican las áreas ocupadas por mallines y en líneas negras las curvas de nivel, con equidistancia de $25 \mathrm{~m}$. B. Vista del mallín M24. C. Vista del mallín M23 (Ubicación en figura 4).

variable a lo largo del eje del mallín, o bien formas irregulares (Fig. 7C). Las dimensiones promedio son de $190 \mathrm{~m}$ de largo y $47 \mathrm{~m}$ de ancho (Fig. 6), y las pendientes varían entre 4 y $8 \%$ (Fig. 7A). El 15\% restante se localiza en la facies externa del plutón (e.g., G18, G19, G26, Figs. 5 y 10A), en este caso ocupando posiciones de cabeceras de los cursos de menor orden, con dimensiones menores (promedios: 

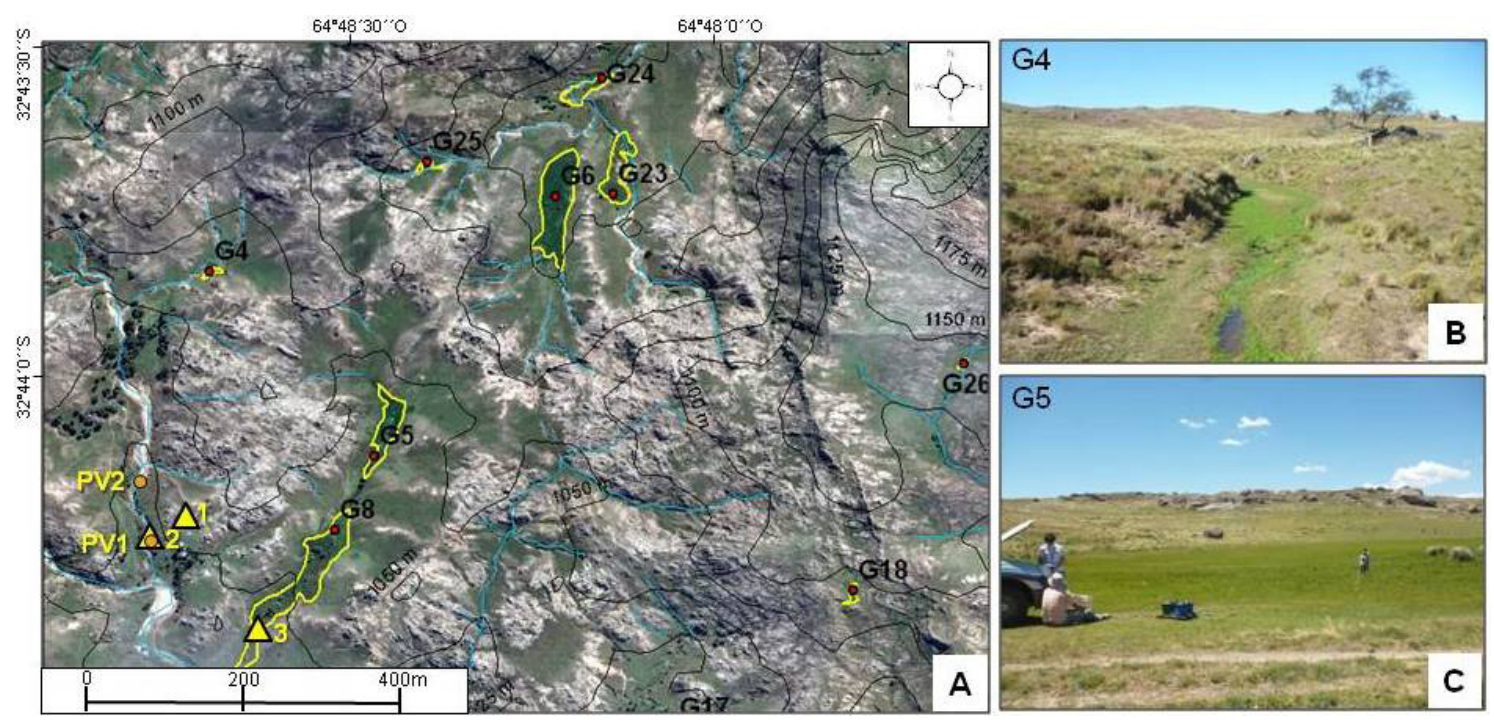

FIG. 10. A. Detalle de un sector de la paleosuperficie granítica (imagen satelital Bing). Con contornos amarillos se indican las áreas ocupadas por mallines, y en líneas negras las curvas de nivel, con equidistancia de $25 \mathrm{~m}$. Se ubican también los perfiles sedimentológicos PV1 y PV2 (círculos naranjas) y las muestras polínicas superficiales (triángulos amarillos). B. Vista del mallín G4, ubicado en el eje de una cárcava. C. Vista del mallín G5 (Ubicación de mallines en figura 4).

$89 \mathrm{~m}$ de largo y $28 \mathrm{~m}$ de ancho), y pendientes entre el 7,4 y $17 \%$.

\subsection{Características sedimentológicas}

Los depósitos analizados (PV1 y PV2, Fig. 10) corresponden a un mallín de fondo de valle, actualmente inactivo por incisión fluvial, la cual ha alcanzado localmente rocas de basamento. La secuencia sedimentaria se expone en las márgenes de un arroyo menor (cuenca de drenaje de $0,61 \mathrm{~km}^{2}$ ) en la Paleosuperficie desarrollada sobre rocas graníticas (Fig. 5D y E). Del material cartográfico disponible puede observarse que en los últimos 50 años, si bien el mallín Puesto Vílchez se encontraba inactivo (por descenso del nivel freático), la densidad de drenaje y la incisión en la cuenca se incrementaron. Para este período se registró una profundización que varía desde aproximadamente $1 \mathrm{~m}$ en el sector de la sección PV1 (terraza erosiva, Fig. 5E) hasta 3-4 m aguas arriba en el colector principal. En los cursos secundarios se originaron cárcavas de hasta $2 \mathrm{~m}$ de profundidad.

De acuerdo a la extensión lateral de las exposiciones sedimentarias, el mallín activo habría tenido una dimensión de ca. $400 \mathrm{~m}$ de largo y $60 \mathrm{~m}$ de ancho y, al menos, 5,40 $\mathrm{m}$ de espesor en la zona más profunda.
Estudios geofísicos en un mallín activo permitieron inferir espesores de $c a .10 \mathrm{~m}$ de sedimentos finos (Andreazzini et al., 2017b).

\subsubsection{Sección PV1 (3244'11,5”S-6448’46,5”O; $1.010 \mathrm{~m}$ s.n.m.)}

Secuencia sedimentaria de $540 \mathrm{~cm}$ de espesor, base cubierta, litológicamente muy homogénea en texturas limo-arenosas, de color grisáceo a negro y muy bioturbada. De base a techo se reconocieron cuatro unidades sedimentarias (I-1, II-1, III-1 y IV-1; Fig. 11).

La unidad I-1 (espesor $70 \mathrm{~cm}$ ) consiste en gravas areno-limosas. Los primeros $10 \mathrm{~cm}$ desde la base están constituidos por gravas finas en una matriz de arena gruesa y limo subordinado, de color castaño (10YR 6/2). Hacia arriba es granodecreciente a arenas limosas y limos, de color negro (10YR 2/1), y con clastos mayores de $1 \mathrm{~cm}$ dispersos.

En contacto neto, apoya la unidad II-1 $(240 \mathrm{~cm}$ de espesor), de color gris (10YR 5/1), con 5,3\% de COT (Fig. 12), y una relación arena:limo:arcilla (A:L:Ar) de 32:58:10. Resultan limos arenosos, de distribución unimodal y asimetría muy positiva $(0,38)$, con $23 \%$ de arenas gruesas y medianas y $77 \%$ de finas-muy finas. Esta unidad muestra, localmente, lentes areno-gravillosas a arenosas finas-limosas, con estratificación gruesa, 


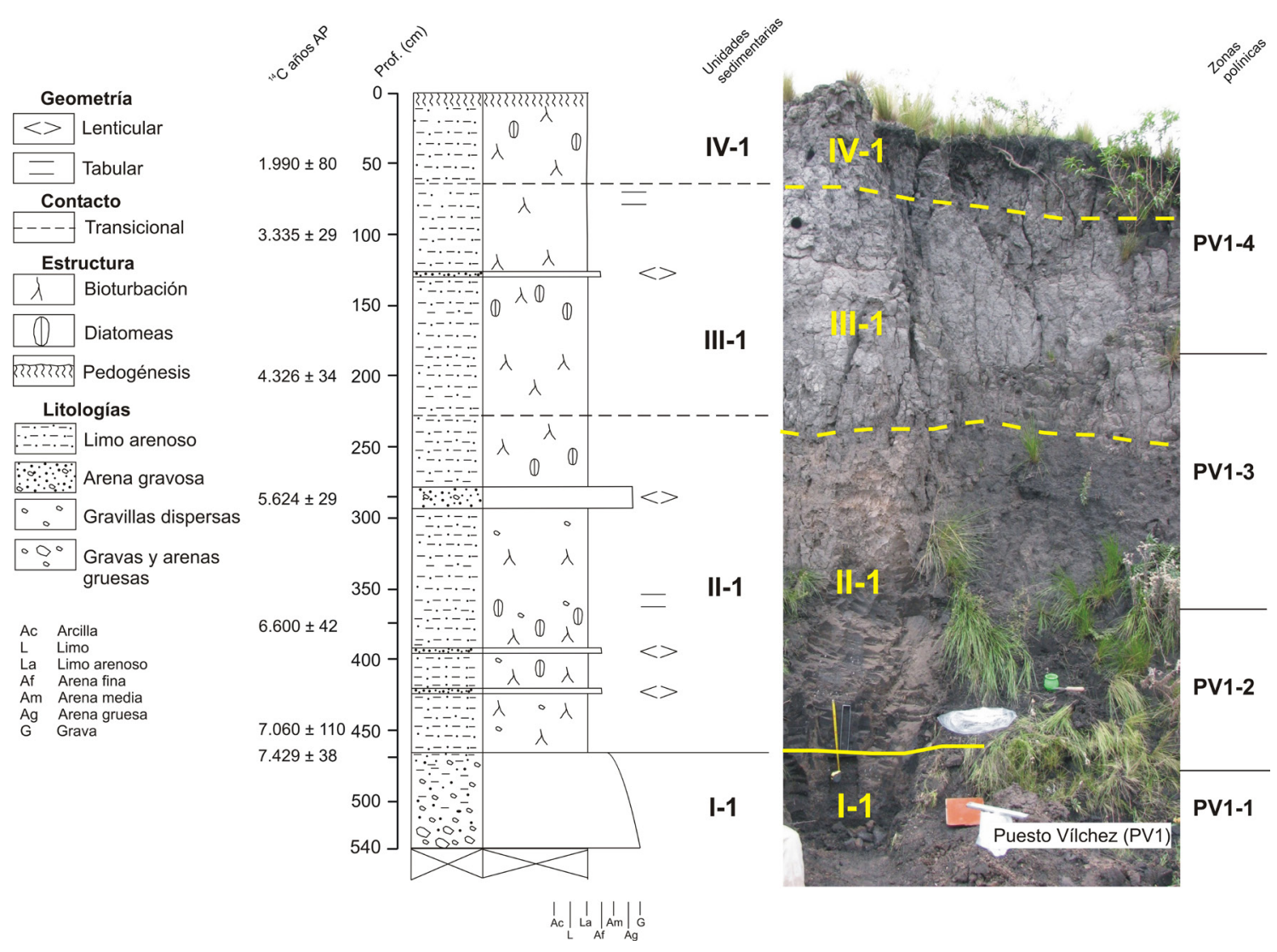

FIG. 11. Perfil estratigráfico y sedimentológico, dataciones radiocarbónicas, vista de la sección PV1 del mallín Puesto Vílchez y zonas polínicas definidas.

espesores de entre 5 y $20 \mathrm{~cm}$, y bajos contenidos de carbono orgánico (COT 0,6\%).

En contacto transicional se apoya la unidad III-1 (170 cm de espesor), de color gris muy oscuro (10YR 3/1), con un COT de 5,1\% y una relación A:L:Ar de 16:71:13 (Fig. 11). Son también limos arenosos, unimodales y simétricos $(0,04)$, en este caso las arenas son dominantemente finas y muy finas ( $85 \%$ ).

La sucesión culmina con la unidad IV-1 $(60 \mathrm{~cm}$ de espesor), de color negro (10YR 2/1), donde el COT alcanza $7,7 \%$ (Fig. 12) y que muestra un significativo desarrollo edáfico. Son limos arenosos algo más finos, unimodales y simétricos $(0,06)$, con una relación A:L:Ar de 11:75:14 y donde la fracción arenosa está formada en más de un $99 \%$ por arenas finas y muy finas.

De acuerdo con las edades radiocarbónicas obtenidas la sucesión del perfil PV1 representa los últimos $c a .9 .000$ cal. años AP (Tabla 1).

\subsubsection{Sección PV2 (3244'7,7”S-6484'47,7”O; 1.012 m s.n.m.)}

Se ubica $100 \mathrm{~m}$ aguas arriba de PV1 a lo largo del arroyo que disectó el mallín. La secuencia sedimentaria presenta $340 \mathrm{~cm}$ de espesor y base cubierta, donde se intercalan depósitos areno-gravosos y limo-arenosos. Se reconocieron tres unidades de base a techo: I-2, II-2 y III-2 (Fig. 12).

La unidad I-2 $(20 \mathrm{~cm}$ de espesor y color marrón muy oscuro 7,5YR 2,5/3) está formada por bancos masivos de arenas fangosas a limos arcillosos con guijarros finos a muy finos dispersos.

Mediante un límite neto e irregular se apoya la unidad II-2 (espesor $125 \mathrm{~cm}$ ) de gravas muy finas a medianas, masivas a groseramente estratificadas en capas horizontales. Los clastos son de composición granítica y presentan entre 2 y $3 \mathrm{~cm}$ de diámetro máximo (muy pocos de $10 \mathrm{~cm}$ ). Entre las gravas se intercalan algunas lentes de arenas limosas, de 


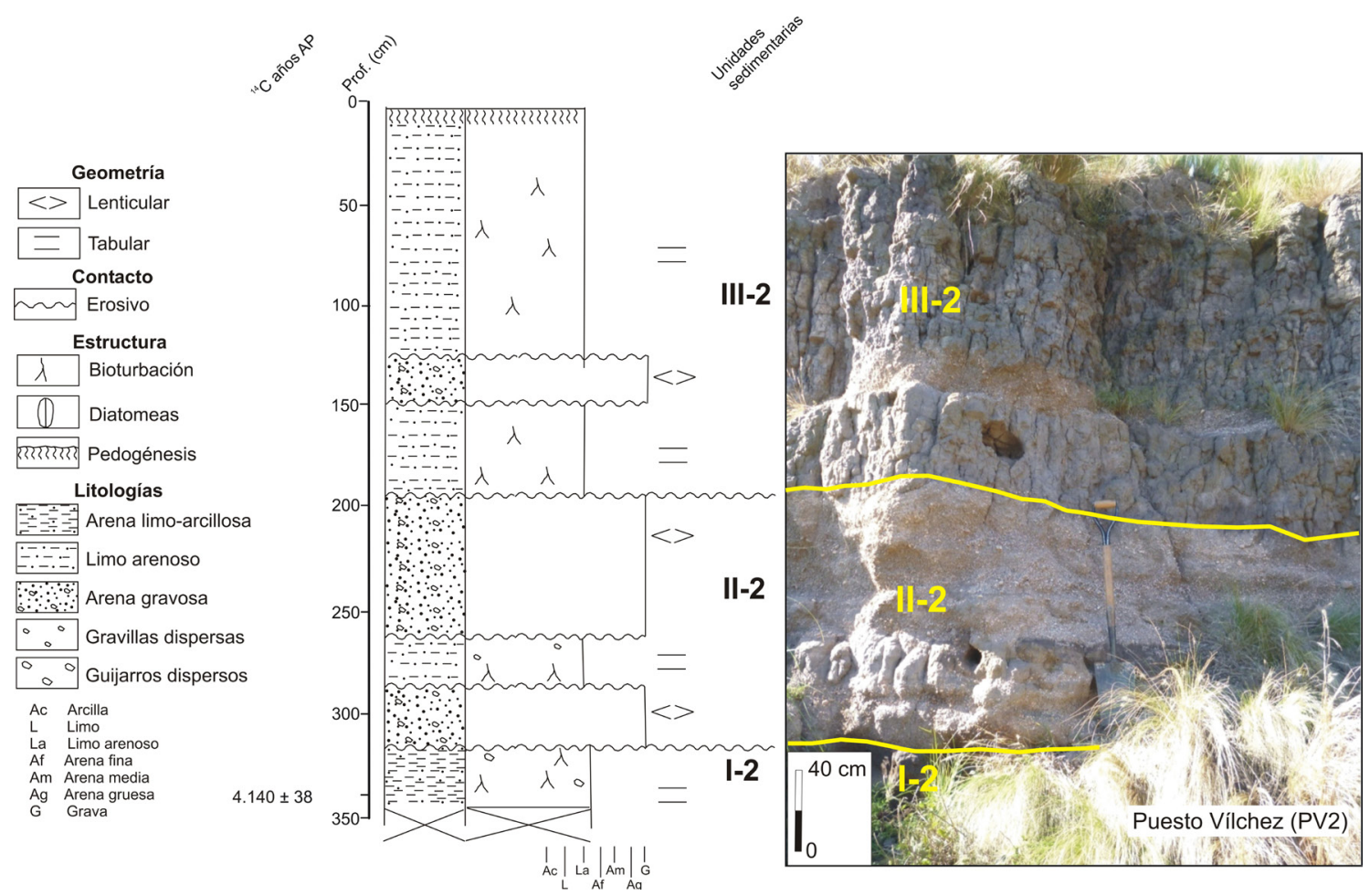

FIG. 12. Perfil estratigráfico y sedimentológico, datación radiocarbónica y vista de la sección PV2 del mallín Puesto Vílchez.

color marrón muy oscuro $(7,5 \mathrm{YR} 2,5 / 3)$ y menos de $15 \mathrm{~cm}$ de espesor.

Lateralmente y aguas abajo, la unidad II-2 se acuña pasando a los depósitos finos incluidos en la suprayacente unidad III-2, con un límite neto y plano. La unidad III-2 (195 cm espesor) está formada por limos arenosos a arcillosos, masivos, de color gris muy oscuro (7,5YR 3/1), con algunas láminas de arenas muy finas a limosas intercaladas. A unos $130 \mathrm{~cm}$ desde el techo de la sucesión se intercala un banco lenticular, de $20 \mathrm{~cm}$ de espesor máximo y menos de $12 \mathrm{~m}$ de continuidad lateral, compuesto por gravas masivas, iguales que los niveles gravosos de la base de la sucesión.

De acuerdo con la edad radiocarbónica obtenida esta sucesión representa los últimos $c a .4 .800$ cal. años AP (Tabla 1).

\subsection{Análisis de diatomeas en la sección PV1}

La unidad II-1 presenta la menor densidad de diatomeas $\left(956 \mathrm{org} / \mathrm{cm}^{2}\right)$, y la mayoría aparecen rotas. Se identificaron allí 11 taxones de los cuales,
Ulnaria ulna, Eunotia sp., Pinnularia borealis y Rhopalodia gibba son las más abundantes (Tabla 2).

La unidad III-1 tiene una densidad de diatomeas mucho mayor que la unidad II-1 $\left(14.588 \mathrm{org} / \mathrm{cm}^{2}\right)$ y la mayor parte muestra buen grado de conservación. Está representada principalmente por Hantzschia amphyoxis, P. borealis, R. gibba y Eunotia sp. (Tabla 2).

La unidad IV-1 muestra la mayor densidad de diatomeas que las precedentes $\left(20.705 \mathrm{org} / \mathrm{cm}^{2}\right)$. Están representadas por Pinnularia sp., Nitzschia frustulum y $H$. amphyoxis (Tabla 2), con un buen estado de conservación.

Teniendo en cuenta que el contenido diatomológico sólo se ha analizado en tres muestras, las inferencias realizadas a partir de estos resultados deben considerarse como un aporte de carácter preliminar y exploratorio.

\subsection{Análisis polínico}

\subsubsection{Relación polen-vegetación actual}

El espectro polínico actual (Fig. 13A) refleja una reducida fracción de la vegetación del área 
TABLA 2. DATOS DEL ANÁLISIS CUANTITATIVO DE DIATOMEAS DE LA SECCIÓN PV1 DEL MALLÍN PUESTO VÍLCHEZ.

\begin{tabular}{|c|c|c|c|c|c|c|}
\hline \multirow{2}{*}{ Taxones } & \multicolumn{2}{|c|}{ Unidad II-1 } & \multicolumn{2}{|c|}{ Unidad III-1 } & \multicolumn{2}{|c|}{ Unidad IV-1 } \\
\hline & Org $/ \mathrm{cm}^{2}$ & $\%$ & Org/ $/ \mathrm{cm}^{2}$ & $\%$ & Org/ $\mathbf{c m}^{2}$ & $\%$ \\
\hline Achnanthidium exiguum (Grunow) Czarnecki & 24,51 & 2,56 & $1.058,80$ & 7,26 & 496,72 & 2,40 \\
\hline Achnanthes inflata (Kützing) Grunow & 0,00 & 0,00 & 382,34 & 2,62 & 156,86 & 0,76 \\
\hline Achnanthidium minutissimum (Kützing) Czarnecki & 0,00 & 0,00 & 0,00 & 0,00 & 209,15 & 1,01 \\
\hline Amphipleura lindheimeri Grunow & 0,00 & 0,00 & 0,00 & 0,00 & 26,14 & 0,13 \\
\hline Amphora sp. & 0,00 & 0,00 & 0,00 & 0,00 & 26,14 & 0,13 \\
\hline Biddulphia laevis Ehrenberg & 0,00 & 0,00 & 0,00 & 0,00 & 26,14 & 0,13 \\
\hline Cocconeis placentula Ehrenberg & 0,00 & 0,00 & 29,41 & 0,20 & 0,00 & 0,00 \\
\hline Cymbella affinis Kützing & 0,00 & 0,00 & 58,82 & 0,40 & 0,00 & 0,00 \\
\hline Encyonema minutum (Hilse) D.G.Mann & 0,00 & 0,00 & 294,11 & 2,02 & 52,29 & 0,25 \\
\hline $\begin{array}{l}\text { Cymbopleura naviculiformis (Auerswald ex Heiberg) } \\
\text { Krammer }\end{array}$ & 0,00 & 0,00 & 29,41 & 0,20 & 0,00 & 0,00 \\
\hline Denticula sp. & 0,00 & 0,00 & 0,00 & 0,00 & 339,86 & 1,64 \\
\hline Diploneis smithii (Brébisson) Cleve & 0,00 & 0,00 & 323,52 & 2,22 & 758,15 & 3,66 \\
\hline Encyonema silesiacum (Bleisch) D.G.Mann & 0,00 & 0,00 & 0,00 & 0,00 & 26,14 & 0,13 \\
\hline Eunotia $\mathrm{sp}_{1}$. & 196,07 & 20,51 & 705,87 & 4,84 & 78,43 & 0,38 \\
\hline Eunotia $\mathrm{sp}_{2}$. & 0,00 & 0,00 & 58,82 & 0,40 & 78,43 & 0,38 \\
\hline Eunotia $\mathrm{sp}_{3}$. & 0,00 & 0,00 & 794,10 & 5,44 & 0,00 & 0,00 \\
\hline Fragilaria sp. & 49,02 & 5,13 & 176,47 & 1,21 & 287,57 & 1,39 \\
\hline Fragilaria vaucheriae (Kützing) J.B.Petersen & 0,00 & 0,00 & 117,64 & 0,81 & 0,00 & 0,00 \\
\hline Frustulia vulgaris (Thwaites) De Toni & 0,00 & 0,00 & 0,00 & 0,00 & 26,14 & 0,13 \\
\hline Geissleria decussis (Østrup) Lange-Bertalot \& Metzeltin & 0,00 & 0,00 & 0,00 & 0,00 & 52,29 & 0,25 \\
\hline Gomphonema parvulum (Kützing) Kützing & 24,51 & 2,56 & 0,00 & 0,00 & 0,00 & 0,00 \\
\hline Gomphonema sp. & 0,00 & 0,00 & 147,06 & 1,01 & 78,43 & 0,38 \\
\hline Hantzschia amphioxys (Ehrenberg) Grunow & 24,51 & 2,56 & $2.735,23$ & 18,75 & 4470,48 & 21,59 \\
\hline $\begin{array}{l}\text { Hippodonta capitata (Ehrenberg) Lange-Bertalot, } \\
\text { Metzeltin \& Witkowski }\end{array}$ & 0,00 & 0,00 & 0,00 & 0,00 & 78,43 & 0,38 \\
\hline $\begin{array}{l}\text { Luticola mutica (Kützing) D.G.Mann in Round, } \\
\text { R.M.Crawford \& D.G.Mann }\end{array}$ & 0,00 & 0,00 & 0,00 & 0,00 & 26,14 & 0,13 \\
\hline Craticula cuspidata (Kutzing) D.G.Mann & 0,00 & 0,00 & 294,11 & 2,02 & 0,00 & 0,00 \\
\hline Navicula sp. & 24,51 & 2,56 & $1.088,21$ & 7,46 & 627,44 & 3,03 \\
\hline Nitzschia dissipata (Kützing) Rabenhorst & 0,00 & 0,00 & 58,82 & 0,40 & 26,14 & 0,13 \\
\hline Nitzschia linearis W.Smith & 0,00 & 0,00 & 58,82 & 0,40 & 0,00 & 0,00 \\
\hline Nitzschia frustulum (Kutzing) Grunow & 24,51 & 2,56 & 529,40 & 3,63 & $5.254,78$ & 25,38 \\
\hline Pinnularia major (Kützing) Rabenhorst & 0,00 & 0,00 & 794,10 & 5,44 & 0,00 & 0,00 \\
\hline Pinnularia borealis Ehrenberg & 147,06 & 15,38 & $2.029,36$ & 13,91 & $2.143,74$ & 10,35 \\
\hline Pinnularia sp. & 49,02 & 5,13 & 117,64 & 0,81 & $4.941,06$ & 23,86 \\
\hline Rhopalodia sp. & 0,00 & 0,00 & 147,06 & 1,01 & 0,00 & 0,00 \\
\hline Rhopalodia gibba (Ehrenberg) Otto Müller & 122,55 & 12,82 & 1970,54 & 13,51 & 156,86 & 0,76 \\
\hline Sellaphora pupula (Kützing) Mereschkovsky & 0,00 & 0,00 & 0,00 & 0,00 & 26,14 & 0,13 \\
\hline Surirella ovalis Brébisson & 0,00 & 0,00 & 29,41 & 0,20 & 52,29 & 0,25 \\
\hline Ulnaria ulna (Nitzsch) Compère & 269,60 & 28,21 & 558,81 & 3,83 & 183,00 & 0,88 \\
\hline Totales & 955,86 & 100,00 & $14.587,89$ & 100,00 & $20.705,40$ & 100,00 \\
\hline
\end{tabular}

En gris se destacan los taxones con porcentajes $\geq 5 \%$. 
de estudio entre los 800 y 1.100 m s.n.m. del sector este del ambiente granítico (Fig. 3). Los pastizales (Estepa herbácea y Pradera) están caracterizados por Poaceae $(>40 \%)$ y Asteraceae subf. Asteroideae $(<30 \%)$ acompañadas por un conjunto de hierbas $(<10 \%)$ representadas principalmente por Lamiaceae, Rubiaceae (Borreria y Mitracarpus) y Caryophyllaceae. Las Cyperaceae están sobrerepresentadas en el mallín activo donde la presencia y permanencia anual de la capa freática en o cerca de la superficie favorece el desarrollo de la vegetación hidrófila. Varios taxones arbóreos y arbustivos están presentes en proporciones $<$ de $5 \%$. Las muestras del Bosque y la Estepa arbustiva están caracterizadas por Asteraceae subf. Asteroideae ( $>30 \%$ ) y Poaceae $(<30 \%)$ y los árboles Celtis, Schinus/Lithrea $(<10 \%)$, Loranthacaeae $(<2 \%)$ que representa a los arbustos parásitos Ligaria y Tripodanthus y trazas de otros árboles y arbustos. Estos taxones están sub-representados debido a que la mayoría de las plantas parentales tienen polinización entomófila (por insectos) y/o ambofilia (por insectos y viento) como Schinus longifolia (Torretta y Basilio, 2009). Celtis es marcadamente anemófilo y puede dispersarse por el viento a largas distancias (Gassman y Pérez, 2006) y en consecuencia contribuir substancialmente en los espectros polínicos de los pastizales. Los altos porcentajes de Asteraceae subf. Asteroideae (60\%) representan la alta abundancia de $H$. alienus que se desarrolla a $c a .840 \mathrm{~m}$ s.n.m., y que correspondería a la Estepa arbustiva que se distribuye en manchones. Los helechos están presentes en todas las unidades de vegetación. Amaranthus-Chenopodioideae, Asteraceae subf. Cichoroideae y Brassicaceae representan tanto a especies exóticas como nativas. Urticaceae representa a Parietaria, una hierba ruderal de amplia distribución relacionada con ambientes disturbados.

\subsubsection{Secuencia polínica fósil}

Los $20 \mathrm{~cm}$ inferiores de la sección PV1 resultaron polínicamente estériles. El resto de las 28 muestras tenía polen suficientemente bien preservado para realizar los recuentos (Fig. 13B). Poaceae domina el espectro polínico y constituye el $45-75 \%$ del conjunto regional del polen y muestra un incremento desde la base al techo. El segundo tipo polínico más abundante es Asteraceae subf. Asteroideae, con porcentajes entre 20 y $50 \%$. Los otros tipos abundantes en diferentes momentos y con valores fluctuantes son Cyperaceae y Amaranthus-Chenopodioideae. Los árboles y arbustos no superan el 10\%. La concentración polínica muestra valores fluctuantes que se incrementa abruptamente a ca. 8.400 cal. años AP y es la más alta de toda la secuencia. El perfil polínico se subdividió en cuatro zonas (PV1-1 a PV1-4) (Fig. 13B).

Zona PV1-1 (515-485 cm, 8.800-8.300 cal. años AP) está caracterizada por la co-dominancia de Poaceae y Asteraceae subf. Asteroideae. Los principales árboles y arbustos están representados.

Zona PV1-2 (470-370 cm, 8.300-7.000 cal. años AP) está marcada por valores altos de Asteraceae subf. Asteroideae. Poaceae fluctúa entre 40 y $60 \%$. Hay un incremento abrupto de AmaranthusChenopodioideae que decrece a partir $c a .7 .500 \mathrm{cal}$. años AP. Cyperaceae muestra un comportamiento semejante a las Amaranthus-Chenopodioideae, pero con menores valores $(<10 \%)$. Hay un incremento relativo de los taxones arbóreos y arbustivos. Gomphrena/Pfaffia y Alternanthera presentan los mayores valores de la secuencia.

Zona PV1-3 (360-175 cm, 7.000-4.700 cal. años AP) está caracterizada por un incremento de Poaceae con valores altos y fluctuantes $(>50 \%)$ y un coincidente decrecimiento de Asteraceae subf. Asteroideae. Los porcentajes de Cyperaceae y AmaranthusChenopodioideae decrecen significativamente $(<5 \%)$ y los taxones arbóreos y arbustivos aparecen de manera saltuaria y en trazas.

Subzona PV1-4 (175-0 cm, 4.700 cal. años AP al presente) está caracterizada por el codominio de Poaceae y Asteraceae subf. Asteroideae. A partir de los 3.200 cal años AP Poaceae alcanza los mayores valores de la secuencia mientras que Asteraceae subf. Asteroideae registra los porcentajes más bajos. Cyperaceae y Amaranthus-Chenopodioideae están presentes con valores fluctuantes. Cyperaceae alcanza los mayores valores de la secuencia polínica a los $c a$. 4.000 cal. años AP. Están representados la mayoría de los árboles y arbustos.

\section{Discusión}

\subsection{Contexto geomorfológico-litológico para el desarrollo de los mallines en la Sierra de Comechingones.}

Los mallines estudiados se desarrollan entre los 890 y 1.850 m s.n.m., en áreas deprimidas, donde se produjo sedimentación aluvial, coluvial y eólica generándose un ambiente con drenaje lento, donde 

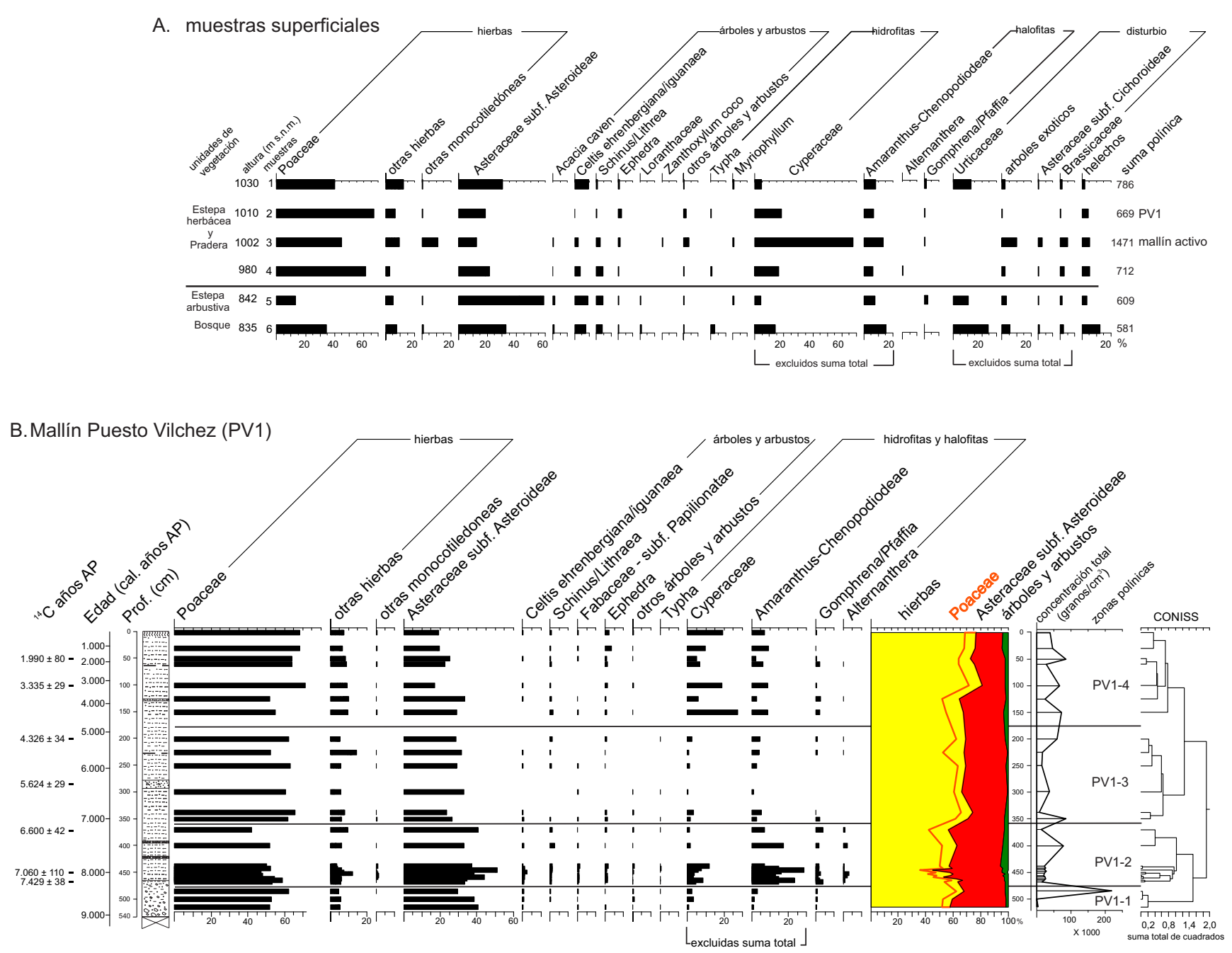

analistas:F. Ciarrocchi y A.R. Prieto

FIG. 13. A. Diagrama polínico actual en porcentaje. B. Secuencia polínica fósil en porcentaje, diagrama integrado, concentración polínica total (granos/cm³) y zonación del perfil PV1. Otros árboles y arbustos: Verbenaceae, Solanaceae, Berberis, Loranthaceae, Acacia. 
descarga el acuífero libre (en medio fracturado o clástico) en concordancia con lo señalado para el desarrollo de mallines en otras áreas de la Argentina (Iriondo et al., 1974; Méndez, 2007; Mazzoni y Rabassa, 2013; Gaitán et al., 2015) y de USA (Lord et al., 2011; Miller et al., 2012). En las secciones PV1 y PV2 estas características se reflejan tanto en la sucesión sedimentaria dominada por materiales finos, como así también en los indicadores biológicos (abundancia y buen estado de conservación de las diatomeas y del polen en la mayoría de las muestras). Estas mismas condiciones se observan en mallines activos, donde el predominio de sedimentos finos (Andreazzini et al., 2017b) con baja conductividad hidráulica (Blarasin et al., 2014), generan la saturación de los materiales y una velocidad de escurrimiento subsuperficial muy lenta. Los mallines ocupan diferentes posiciones de la red de drenaje como cabeceras de cursos de bajo orden, fondos de valles, posiciones bajas en laderas y confluencias. Secundariamente, algunos se localizan en depresiones aisladas en áreas de interfluvio como las pampas de altura y los sectores cumbrales (Fig. 4). Los mallines de fondo de valles y áreas deprimidas tienen, en general, mayor extensión, una mayor acumulación de sedimentos y un régimen hidrológico más estable que los que se ubican en zonas con pendientes más pronunciadas y áreas de cabeceras, ya que los primeros presentan mayor área de captación hidrológica y constituyen la zona de descarga principal del acuífero libre (en medio fracturado y clástico).De este modo estos mallines más extensos son, en general, más resilientes frente a fluctuaciones climáticas. Oxman et al. (2015) observaron este comportamiento comparando vegas con distintas áreas de captación en la región de la puna del norte de la Argentina.

Así, la topografía, la geomorfología e hidrología tienen una clara influencia en las dimensiones, formas y distribución de los mallines, como ha sido observado en otras regiones (Germanoski et al., 2011; Miller et al., 2012; Mazzoni y Rabassa, 2013; Gaitán et al., 2015). Los mallines del área de estudio, que pueden ser extrapolados a los desarrollados en las Sierras Pampeanas de Córdoba y San Luis (Scopel et al., 2017), poseen en general menores dimensiones que los de las regiones andina y patagónica de la Argentina. Los estudiados en este trabajo se asocian a diferentes geoformas fluviales y la recarga principal son las lluvias, en cambio en la región andina se vinculan a morfologías glaciares y periglaciares y en la región extra-andina a fondos de valles fluviales, planicies de inundación y planicies lávicas; ambos tienen mayor recarga por precipitaciones nivales y/o deshielo (Iriondo et al., 1974; Mazzoni y Rabassa, 2013; Gaitán et al., 2015).

En relación con la influencia litológica sobre la distribución y dimensiones de los mallines estudiados, se observó que en aquellos presentes en la Paleosuperficie desarrollada sobre rocas metamórficas, con bajo grado de incisión fluvial (unidad C, Fig. 2, y Fig. 4), la presencia de cubiertas loéssicas/loessoides, las bajas pendientes, y la escasa profundidad de las rocas del basamento, favorecen la infiltración y saturación de los sedimentos dominantemente limosos de baja conductividad hidraúlica, originando los mallines de mayor extensión areal, en cabeceras y fondo de valle (ejes de cárcavas). En las unidades A y B (Fig. 2) (Paleosuperficie desarrollada sobre rocas graníticas y Paleosuperficie desarrollada sobre rocas metamórficas, con alto grado de incisión fluvial, respectivamente, Fig. 4), se observan más rasgos erosivos, un incremento de afloramientos rocosos, una disminución de la cubierta loéssica/loessoide y son más comunes las secuencias aluviales y coluviales, en comparación con las pampas de altura (Unidad C, Fig. 2) e inferimos que por ello se reduce la cantidad y tamaño de los mallines, pero con marcadas diferencias en ambos paisajes. Las rocas graníticas, especialmente la facies interna del plutón Alpa Corral (Fig. 2), poseen mayor susceptibilidad de meteorización que las metamorfitas de alto grado del Complejo Monte Guazú, y, por lo tanto, generan mayor disponibilidad de regolito. Las geoformas de los relieves graníticos incluyen variedades que posibilitan el almacenamiento de sedimentos (valles amplios, superficies areolares). Así, las laderas y fondos de valles/depresiones contienen sucesiones de hasta 5-8 $\mathrm{m}$ de sedimentos loéssicos/loessoides con altos porcentajes de clastos areno-gravosos provenientes del basamento. Estos depósitos favorecen la infiltración del agua de escorrentía (sistemas efímeros) y conforman acuíferos en medio clástico donde descarga el agua de fisuras/fracturas en rocas, potenciando la instalación de mallines.

Por su parte, el ambiente metamórfico produce menor cantidad de regolito, y éste es dominantemente psefítico grueso (bloques). Se observa que domina el escurrimiento superficial sobre la infiltración, el agua circulante en el medio rocoso descarga directamente como vertientes que aportan a los 
sistemas superficiales ya que no existen sucesiones sedimentarias significativas que alojen acuíferos, los procesos de incisión fluvial son activos, los cursos en general son permanentes y generan valles angostos, de alta dinámica, donde prevalece el transporte sobre el almacenamiento de sedimentos, condiciones poco propicias para la instalación de mallines.

Observaciones similares fueron realizadas por Miller et al. (2012) en Sierra Nevada (USA), quienes determinaron que los mallines son más frecuentes en zonas de rocas menos resistentes a la meteorización, donde dominan la producción y la acumulación de sedimentos de tamaño relativamente fino y la recarga de agua subterránea. Por el contrario, en las zonas con litologías más resistentes a la meteorización se producen clastos más grandes y dominan los procesos de transporte y escurrimiento superficial.

\subsection{Reconstrucción paleoambiental del área del mallín Puesto Vílchez}

Entre $c a .14$ y 11 ka AP se habría desarrollado un periodo árido y frío en la provincia de Córdoba (Kröhling y Carignano, 2014) coincidente con avances glaciales en los Andes del sur (Rabassa, 2008) y en la zona cordillerana de la región de Atacama ( 26ㅇ-29 $\mathrm{S}$ ) (Zech et al., 2006, 2007; Maldonado y Rozas, 2008). Los depósitos loéssicos y loessoides del piedemonte oriental de la Sierra de Comechingones y de las llanuras orientales (Cantú, 1992) y de las pampas de altura de la zona de estudio (Andreazzini et al., 2013) responderían a estas condiciones. Durante este período habrían existido procesos erosivos que removilizaron los depósitos sedimentarios previos en el área de estudio, exponiendo las rocas del basamento cristalino. En el sector norte de las Sierras Pampeanas de Córdoba, este periodo se asocia con depósitos loessoides (Krapovickas y Tauber, 2016).

Posteriormente a ca. $9 \mathrm{ka} \mathrm{AP,} \mathrm{se} \mathrm{habrían} \mathrm{iniciado}$ condiciones subtropicales húmedas y temperaturas mayores que las actuales en los ambientes serranos y periserranos del centro de la Argentina (Kröhling y Carignano 2014; Sanabria et al., 2014; Strasser et al., 2014; Krapovickas y Tauber, 2016), las que se habrían extendido hasta ca. 5 ka AP (Kröhling y Carignano, 2014), aunque variables en las pampas de altura (Sanabria et al., 2014; Krapovickas y Tauber, 2016). En el área de estudio, los depósitos de gravas areno-limosas (unidad I-1, sección PV1, Fig. 11) indican procesos de agradación en los valles con anterioridad a $c a .8 .400$ cal. años AP. La ausencia de polen en la base de la unidad I-1 ( $20 \mathrm{~cm}$ basales) está relacionada con la granulometría del sedimento $y$, en consecuencia, con la velocidad de la corriente que habría afectado la depositación del polen.

El espectro polínico de la parte superior de esta unidad (zona PV1-1, Fig. 13) sugiere el desarrollo de pastizales próximos a comunidades arbustivas y las comunidades de hidrófitas permiten inferir que no hubo agua estancada. La alta concentración polínica en el tope de esta unidad (Fig. 13) sugiere un momento de baja tasa de sedimentación que es coincidente con el cambio litológico de gravas y arenas a limos arenosos y marca el comienzo de la formación del mallín Puesto Vílchez a los ca. 8.400 cal. años AP.

El resto de la sucesión PV1 (unidades II-1, III-1 y IV-1, Fig. 11) representa los productos distales de escorrentías superficiales, las que depositaron su carga gravosa y la mayor parte de la arenosa más gruesa en las zonas de borde (unidades I-2 y II-2 de PV2, Fig. 12) antes de alcanzar el fondo del valle en donde se acumularon las fracciones más finas por flujos de muy baja energía (sección PV1, Fig. 11). El establecimiento de condiciones húmedas a ca. 8.400 cal. años AP, habría aumentado gradualmente la recarga de los acuíferos en el medio fracturado. Consecuentemente, la aparición de un mayor número de sitios de descarga en las pendientes y fondos de valles, favorecieron la instalación de la vegetación y el aporte de materia orgánica al sustrato. Estas condiciones, a su vez, propiciarían el entrampamiento de sedimentos finos eólicos (Pigati et al., 2014) que explican el predominio de limos en la sucesión. Esta interpretación está reforzada por la presencia de diatomeas de agua dulce a salobre con altas proporciones de epífitas, acompañadas por especies ticoplanctónicas y bentónicas en las tres muestras analizadas (Tabla 2). Las asociaciones sugieren la existencia de un cuerpo de agua somero con vegetación, con fluctuaciones en el nivel y la salinidad del agua y baja carga de nutrientes en un ambiente ácido-neutral durante la mayor parte del Holoceno.

El registro polínico y las evidencias sedimentarias del área del mallín Puesto Vílchez señalan tres cambios importantes con posterioridad a $c a .8 .300$ cal. años AP. Entre 8.300 y 7.000 cal. años AP (zona PV1-2, Figs. 11 y 13) hubo un mayor desarrollo de una comunidad arbustiva de Asteraceae subf. 
Asteroideae que junto con la presencia de varios árboles y arbustos (Celtis, Schinus/Lithraea, Fabaceae, Ephedra), sugieren una mayor presencia de la estepa arbustiva en esa altitud, donde actualmente es escasa. Esto se explicaría por temperaturas más altas que las actuales y un decrecimiento de los eventos de heladas que habrían ocasionado un aumento en la tasa de crecimiento de los arbustos (Giorgis et al., 2013). Localmente, se desarrolló una comunidad de halófitas señalada por el incremento notable y fluctuante de Amaranthus-Chenopodioideae y la presencia de Gomphrena/Pfaffia y Alternanthera. Esto sugiere la salinización del suelo y condiciones variables y limitantes de agua, indicadas también por los valores fluctuantes de Cyperaceae. La presencia de Typha reafirma la formación de zonas inundables o con muy lento desplazamiento del agua, poco profundas. Las fluctuaciones en las proporciones de estos taxones locales enfatizan una inestabilidad ambiental en términos de humedad y condiciones temporariamente secas.

Entre ca. 7.000 y 4.700 cal. años AP (zona PV1-3, Fig. 13) se desarrollaron pastizales semejantes a los actuales de la estepa herbácea y la pradera. Los taxones arbóreos y arbustivos aparecen en trazas, indicando su presencia de forma dispersa en el área y la estepa arbustiva presenta un menor desarrollo en esta altitud con respecto al período anterior. Las comunidades de hidrófitas y halófitas se redujeron notablemente señalando una escasa disponibilidad de agua en el sitio o un nivel freático más profundo. La elevación (o profundidad) del nivel freático es el factor de control dominante de las comunidades de plantas en la mayoría de los mallines (Lord et al., 2011). Esto podría relacionarse con una reducción significativa principalmente de las precipitaciones de verano y otoño con respecto al presente, probablemente debido a un debilitamiento de la circulación monzónica y de la Zona de Convergencia Intertropical (Berman et al., 2016). En cambio, las precipitaciones de primavera habrían sido significativamente más alta que las actuales, asociadas con el incremento de la insolación (Berman et al., 2016). Este incremento pudo mantener las temperaturas semejantes a las actuales, pero no fueron suficientes para permitir un mayor desarrollo de las estepas arbustivas a esta altitud.

Aunque la duración de las condiciones de extrema sequía y niveles muy bajos de la Laguna Mar Chiquita, provincia de Córdoba (Fig. 1), señaladas por un abrupto balance hidrológico negativo, no ha sido determinada, estas condiciones ocurrieron con anterioridad a $4.700 \mathrm{cal}$. años AP (Piovano et al., 2009) y se corresponden con un clima más seco que el presente en una amplia área del centro de la Argentina durante el Holoceno medio (Mancini et al., 2005; Forman et al., 2014; Berman et al., 2016). Las intercalaciones de facies más gruesas en la sección superior de la unidad II-1 (Fig. 11), representan depósitos de escorrentías superficiales de mayor energía, que estarían asociados a lluvias torrenciales en aquellos períodos más secos. Esto explicaría el menor contenido de diatomeas (Tabla 2) y su mal estado de preservación en la muestra de la unidad II-1. Como los taxones más abundantes son de hábito bentónico, la mayor velocidad del agua generaría el arrastre y rotura de los organismos, con la consecuente disminución de su densidad. Los mayores porcentajes de Ulnaria ulna (epífita $28,2 \%$, Tabla 2), se explicarían por la resistencia de los frústulos a mayores velocidades de circulación de agua (Luque y Martínez de Fabricius, 2003; Gari y Corigliano, 2004).

Con posterioridad a ca. 4.700 cal. años AP, ocurrió un cambio en las condiciones locales del mallín Puesto Vílchez indicado por el incremento de las hidrófitas, especialmente Cyperaceae que aparece con valores altos y fluctuantes, que se extiende hasta la actualidad (zona PV1-4, Fig. 13). Esto señala disponibilidad de agua y un aumento en la humedad del suelo, pero variable, sin llegar a condiciones secas, relacionada con condiciones frías y húmedas semejantes a las actuales. Esto también se refleja en la reducida comunidad de halófitas (Fig. 13) y en el mayor porcentaje de COT en la unidad IV-1. Las comunidades de diatomeas en las unidades III-1 y IV-1 (Tabla 2) reflejan un ambiente de humedal con una lenta circulación de agua o estancamiento, manifestado en parte por el buen estado de preservación de los organismos y por la mayor densidad en comparación con la unidad II-1. El incremento de las diatomeas aerófilas como Hantzschia amphioxys y Pinnularia borealis, indicadoras de momentos de desecación, sugiere que el cuerpo de agua se somerizó (Hassan et al. 2004). La unidad IV-1 presenta una comunidad de diatomeas muy semejante a la de la unidad III-1, aunque algunos taxones como $H$. amphioxys, Nitzschia frustulum y Pinnularia sp., sugieren el desarrollo de comunidades algales en un estado avanzado de sucesión ecológica. Esto indicaría que el ambiente de aguas someras con vegetación asociada se mantuvo 
durante un período de tiempo prolongado (Passy, 2007; Wu et al., 2009).

Las características texturales, el contenido de COT, el registro polínico y los restos de diatomeas (Fig. 11, Tabla 2) se corresponden con la facies depositacionales de humedales (descriptos como wetlands en Liutkus y Ashley, 2003; y wet meadows en Pigati et al., 2010, 2014).

La secuencia sedimentaria de la sección PV2 (Fig. 12), ubicada en una posición de borde, permitió inferir fluctuaciones espaciales del mallín para los últimos ca. 4.800 cal. años AP. Las lentes gravosas representan productos de corrientes tractivas de alta energía, que sugieren una contracción del área ocupada por el mallín. En cambio, las unidades finas (Fig. 12) son el resultado de flujos de escorrentía distal y entrampamiento de limos eólicos en un ambiente de baja energía e indican la expansión del mallín. Esta alternancia reafirma la variabilidad ambiental para este período. El cambio en las condiciones locales del mallín es coincidente con el reemplazo de plantas $\mathrm{C} 4$ por plantas $\mathrm{C} 3$ a $3.870 \pm 210$ cal. años $\mathrm{AP}$, que fue relacionado con cambios del clima hacia condiciones más frías y húmedas en la región central de la Argentina (Silva et al., 2011).

Para el área periserrana, en cambio, se han inferido condiciones climáticas más secas y cálidas que las actuales entre $c a$. 4/3,5 y 1,4/1 ka AP (Kröhling y Carignano, 2014; Forman et al., 2014), señalado como intervalo Neoglacial por Kröhling y Carignano (2014). Existen evidencias de cinco períodos de avances Neoglaciales en los Andes del sur con posterioridad a ca 5.000 cal. años AP y hasta los siglos XVII-XIX (Aniya, 2013). Aunque la cronología de estos avances glaciales en Patagonia aún se utiliza como tendencias regionales amplias, hay ejemplos de avances glaciales datados fuera de esos períodos (Rabassa, 2008). En los Andes a ca. $35^{\circ} \mathrm{S}$ el primer avance Neoglacial ocurrió a ca. 6.600-6.300 cal. años AP y un reavance de magnitud similar a 5.600-4.600 cal. años AP y dos posteriores, a ca. 2.800-2.100 cal. años AP y durante la Pequeña Edad de Hielo (Espizua, 2005; Solomina et al., 2015). Las fluctuaciones de los glaciares en el sur de América del Sur no siguieron, en general, las tendencias orbitales, pero fluctuaron a una frecuencia más alta posiblemente desencadenada por distintos patrones de teleconexiones (Solomina et al., 2015). Se ha sugerido que la variabilidad de la precipitación sería el principal impulsor de las fluctuaciones Neoglaciales del campo de hielo de la Patagonia Norte aunque se necesita más información para probar esta hipótesis en esta región pobremente documentada (Solomina et al., 2015) y poder extrapolar estos resultados a áreas como las Sierras Pampeanas.

La persistencia de condiciones más húmedas en el ambiente serrano que en el periserrano podría relacionarse con nevadas invernales, las que mantendrían la recarga del agua subterránea $\mathrm{y}$, por consiguiente, la presencia de mallines y el régimen hidrológico permanente en algunos ríos y arroyos. La variabilidad climática aquí inferida para el sector sur de la Sierra de Comechingones durante el Holoceno también ha sido interpretada para las pampas de altura ubicadas al norte del área de estudio (Sanabria et al., 2014; Krapovickas y Tauber, 2016). Esta variabilidad climática también fue sugerida para la Sierra de Comechingones por Andreazzini et al. (2017a), quienes estudiaron un pedocomplejo datado entre $8.310 \pm 110{ }^{14} \mathrm{C}$ años AP (9.296 cal. años AP) y $4.330 \pm 130{ }^{14} \mathrm{C}$ años AP (4.938 cal. años AP) en la cuenca del río La Tapa (1.630 m s.n.m.). En esta misma área, se describió un paleosuelo con horizontes $\mathrm{Bt}$ y presencia de óxidos de hierro, que fueron relacionados con condiciones climáticas húmedas y cálidas (Andreazzini et al. 2013). Sobre este paleosuelo y rellenando grietas que lo atraviesan se formó un calcreto, fechado en $4.180 \pm 80{ }^{14} \mathrm{C}$ años AP (4.702 cal. años AP), que sugiere condiciones más secas (Andreazzini et al., 2013). En las pampas de altura de la Sierra de San Luis se identificaron, para el Holoceno tres niveles de paleosuelos entre $c a$. 3 y 1,3 ka AP que indican condiciones edafoclimáticas de mayor intensidad que las actuales (Strasser et al., 2014).

El inicio del proceso de incisión en el área estudiada y consecuente integración del sistema a la red de drenaje actual, habría ocurrido en las últimas centurias, en concordancia con lo señalado en otros sistemas fluviales de la región (Degiovanni et al., 2009; Doffo et al., 2010; Magnante et al., 2014). En el valle estudiado, la cartografía disponible y mapeo geomorfológico indican que el proceso de incisión y drenado del mallín por descenso del nivel freático habría ocurrido con anterioridad a la década de 1970. A partir de este momento el incremento en la tasa de incisión estaría asociado con un aumento de las precipitaciones en la región desde la década de 1970 (Blarasin, 2003; Andreazzini, 2015). El incremento de la actividad ganadera en el sector 
serrano y la ocurrencia de incendios forestales que involucran la quema de importantes áreas de bosques y pastizales naturales (Ministerio de Ambiente y Desarrollo Sustentable, 2016), favorecieron el aumento de los caudales líquidos y sólidos de los cursos de agua (Andreazzini, 2015; Andreazzini et $a l ., 2014)$ y potenciaron los procesos de incisión. En función de estas observaciones el inicio de la incisión y drenado del humedal podría suponerse han sido aún más recientes.

Los cambios en la vegetación y el desarrollo del mallín durante el Holoceno en el área de estudio estarían principalmente condicionados por variaciones en la temperatura que influenciaría las condiciones húmedas y secas. Las inferencias climáticas señaladas en este trabajo refuerzan las evidencias propuestas por Andreazzini et al. (2017a) de que las condiciones climáticas en las pampas de altura en el sector serrano de las Sierras de Comechingones muestran patrones diferentes con las llanuras periserranas circundantes latitudinalmente equivalentes durante el Holoceno.

\section{Conclusiones}

- En las Sierra de Comechingones, el mayor desarrollo de los mallines se vincula a ambientes geomorfológicos donde existen condiciones de menor actividad morfodinámica, como ocurre en los relictos de superficies erosivas y fondos de valles y, secundariamente, a áreas de cabeceras de cursos de bajo orden y laderas. Estas condiciones se ven favorecidas en el área de rocas graníticas, en especial en la facies interna, y en los depósitos loéssicos/loessoides preservados en las pampas de altura.

- La fuente principal de los materiales que conforman los depósitos de mallines proviene de la removilización de depósitos loéssicos/ loessoides cuaternarias presentes en el sector serrano y, secundariamente, de la suspensión eólica (entrampados en el humedal) y aportes producto de la alteración de las rocas del basamento cristalino.

- Durante la mayor parte del Holoceno prevalecieron condiciones de agradación en el ambiente serrano. Las secuencias estratigráficas analizadas permiten inferir la alternancia de periodos de mayor o menor integración de la red de drenaje. Las sucesiones de mallín se asocian a periodos de estancamiento/ baja circulación superficial (menor conectividad hidrológica superficial), donde estas depresiones actuarían como nivel de base local. Por otro lado, los niveles areno-gravosos del eje del valle se vinculan a escurrimientos encauzados (mayor conectividad hidrológica superficial, mayor integración de la red de drenaje). Los procesos de incisión e integración de las redes de drenaje que ocurrieron en las últimas centurias iniciaron la desactivación y la pérdida de estos humedales.

- El registro sedimentológico, polínico y diatomológico, sugieren la persistencia del ambiente de humedal en los sectores altos de las Sierras de Comechingones durante gran parte del Holoceno, los que han contraído y ampliado sus áreas como respuesta a la variabilidad ambiental.

- La reconstrucción paleoambiental del mallín Puesto Vílchez sugiere que las condiciones climáticas fueron variables durante gran parte del Holoceno, principalmente relacionadas con cambios en la disponibilidad de agua y la temperatura. Previo a ca. 8.400 cal. años AP ocurrieron condiciones de alto potencial erosivo relacionadas a períodos relativamente más secos que el presente, con escurrimientos superficiales esporádicos y descenso del nivel freático. Entre 8.300 y 7.000 cal. años AP un mayor desarrollo de la estepa arbustiva en esa altitud está relacionado con temperaturas más altas que las actuales y un decrecimiento de los eventos de heladas. Entre $c a .7 .000$ y 4.700 cal. años AP se registró el período en el que las condiciones fueron más secas que las actuales al menos temporariamente, en concordancia con un clima más seco que el presente a los $c a .6 .000$ cal. años AP en una gran área del centro de la Argentina. Con posterioridad a ca. 4.700 cal. años AP se establecieron condiciones frías y húmedas semejantes a las actuales. Los cambios ambientales están principalmente condicionados por variaciones en la temperatura que influenciaría las condiciones húmedas y secas.

- El incremento en la precipitación media anual en la región desde la década de 1970, junto con los recurrentes incendios forestales, muchos de ellos antrópicos, han aumentado el escurrimiento, potenciaron los procesos de incisión y ha puesto en riesgo la preservación de estos sistemas de alto valor ambiental.

\section{Agradecimientos}

Este trabajo ha sido realizado mediante proyectos de investigación financiados por la Secretaría de Ciencia 
y Técnica de la Universidad Nacional de Río Cuarto (SECyT-UNRC), del Ministerio de Ciencia y Tecnología de la provincia de Córdoba (MINCyT) y de la Agencia Nacional de Promoción Científica y Tecnológica (ANPCyT), PID 35/08 y PICT 950/14. A H. Frazer y F. Ciarrocchi por su colaboración en parte de los trabajos de campo. A N. Gari por su colaboración en el análisis diatomológico. A M. Giorgis y M. Espinosa por sus comentarios y sugerencias sobre la interpretación de la vegetación y de las diatomeas, respectivamente. A L. Rojo, J.M. Krapovickas, un revisor anónimo y al editor por los comentarios y sugerencias constructivas.

\section{Referencias}

Andreazzini, M.J. 2015. Análisis de los procesos de ajuste en sistemas fluviales serrano-pedemontanos frente a cambios ambientales. Cuenca del río Las Cañitas, Córdoba, Argentina. Tesis Doctoral (Inédito), Universidad Nacional de Río Cuarto, Departamento de Geología: 438 p.

Andreazzini, M.J.; Degiovanni, S.B. 2014. Geomorphology of paleosurfaces in the Sierras de Comechingones, Central Pampean Ranges, Argentina. In Gondwana Landscapes in Sourthern South America (Rabassa, J.; Ollier, C.; editores), Springer Verlag: 305-330. Dordrecht.

Andreazzini, J.; Degiovanni, S.; Spalletti, P.; Irigoyen, M. 2014. Producción de sedimentos en una cuenca de Sierras Pampeanas, Córdoba, Argentina: Estimación para distintos escenarios. Aqua-LAC Revista del Programa Hidrológico Internacional para América Latina y el Caribe de la UNESCO 6 (1): 38-49.

Andreazzini, M.J.; Degiovanni, S.B.; Cantú, M.P.; Grumelli, M.T.; Schiavo, H. 2013. Análisis e interpretación paleoambiental de secuencias del Cuaternario superior en pampas de altura del sector centro-sur de la Sierra de Comechingones, Córdoba, Argentina. Latin American Journal of Sedimentology and Basin Analysis 20 (2): 65-84.

Andreazzini, M.J.; Degiovanni, S.B.; Echevarria, K.V. 2017 a. Paleoenvironmental reconstruction of Quaternary valleyfill successions in summit paleosurfaces of southern Sierras Pampeanas (Córdoba Province, Argentina). Quaternary International 442 (Part A): 50-58.

Andreazzini, M.J.; Degiovanni, S.B.; Tripaldi, A.; Felizzia, J.; Doffo, N.C. 2017b. Caracterización geomorfológicasedimentológica de mallines en un sector del batolito Cerro Áspero, Sierra de Comechingones, Córdoba. Actas de resúmenes. In Congreso Geológico Argentino, No. 20, Simposio 7: 1-3. San Miguel de Tucumán.
Aniya, M. 2013. Holocene glaciations of Hielo Patagónico (Patagonia Icefield), South America: A brief review. Geochemical Journal 47: 97-105.

Ashley, G.M.; Mworia, J.M.; Muasya, A.M.; Owen, R.B.; Driese, S.G.; Hover, V.C.; Renaut, R.W.; Goman, M.F.; Mathai, S.; Blatt, S.H. 2004. Sedimentation and recent history of a freshwater wetland in a semi-arid environment: Loboi Swamp, Kenya, East Africa. Sedimentology 51: 1301-21.

Bamonte, F.P.; Mancini, M.V. 2011. Palaeoenvironmental changes since Pleistocene-Holocene transition: pollen analysis from a wetland in Southwestern Patagonia (Argentina). Review of Paleobotany and Palynology 165 (1-2): 103-110.

Berman, A.L.; Silvestri, G.E.; Rojas, M.; Tonello, M.S. 2016. Accelerated greenhouse gases versus slow insolation forcing induced climate changes in southern South America since the Mid-Holocene. Climate Dynamics 48 (1-2): 387-404. doi: 10.1007/s00382-0163081-z.

Blarasin, M. 2003. Geohidrología ambiental del Sur de Córdoba, con énfasis en la ciudad de Río Cuarto y su entorno rural. Tesis Doctoral (Inédito), Universidad Nacional de Río Cuarto, Departamento de Geología: $377 \mathrm{p}$.

Blarasin, M.; Cabrera, A.; Matteoda, E.; Frontera, H.; Aguirre, M.; Maldonado, L.; Becher Quinodoz, F.; Giuliano Albo, J. 2014. Recursos Hídricos Subterráneos Parte I: Aspectos litológicos, hidráulicos, cambios de régimen y reservas de los principales acuíferos. In Relatorio Congreso Argentino de Geología, No. 19, Geología y Recursos Naturales de la Provincia de Córdoba (Martino, R.; Guereschi, A.; editores). ALSAPEMA S.A.: 747-821. Córdoba.

Brinson, M.; Malvárez, I. 2002. Temperate freshwater wetlands: types, status, and threats. Environmental Conservation 29: 115-133.

Bull, W. 1997. Discontinuous ephemeral streams. Geomorphology 19: 227-276.

Cabrera, A.L. 1976. Regiones Fitogeográficas Argentinas. Enciclopedia de Agricultura y Ganadería. ACME: 85 p. Buenos Aires.

Cabido, M.; Acosta, A.; Díaz, S.; Pucheta, E.; Gonzalez Albarracin, C. 1996. Factores estructuradores en pastizales serranos del centro de Argentina. In Biodiversidad y funcionamiento en pastizales y sabanas en América Latina (Sarmiento, G.; Cabido, M.; editores). CYTED y CIELAT, 101-130. Mérida.

Cantero, J.J.; Cabido, M.; Núñez, C.; Petryna, L.; Zak, M.; Zobel, M. 2001. Clasificación de los pastizales 
de suelos sobre rocas metamórficas de las Sierras de Córdoba, Argentina. Kurtziana 29: 27-77.

Cantú, M.P. 1992. Provincia de Córdoba. In El Holoceno en la Argentina (Iriondo, M.; editor). Editorial CADINQUA 1: 1-16. Paraná.

Capitanelli, R.G. 1979. Clima. In Geografía física de la Provincia de Córdoba (Vázquez, J.; Miatello, R.; Roque, M.; editores). BOLDT: 45-138. Córdoba.

Carignano, C.; Cioccale, M.; Rabassa, J. 1999. Landscape Antiquity of the Central-Eastern Sierras Pampeanas (Argentina): Geomorphological Evolution since Gondwanic Times. Zeitschrift fur Geomorphologie, Supplementband 118: 245-268.

Carignano, C.; Krölhing, D.; Degiovanni, S.; Cioccale, M. 2014. Geomorfología. In Relatorio Congreso Argentino de Geología, No. 19, Geología y Recursos Naturales de la Provincia de Córdoba (Martino, R.; Guereschi, A.; editores). ALSAPEMA S.A.: 747-821. Córdoba.

Chambers, J.C.; Miller, J.R. 2004. Great Basin riparian ecosystems: ecology, management, and restoration. Island Press: 303 p. Washington.

Chambers, J.C.; Miller, J.R. 2011. Geomorphology, hydrology, and ecology of Great Basin meadow complexes. Implications for management and restoration. General Technical Report RMRS-GTR-258. Fort Collins, CO: U.S. Department of Agriculture, Forest Service, Rocky Mountain Research Station: 125 p.

Coniglio, J.E.; D’eramo, F.J.; Pinotti, L.P.; Demartis, M.; Agulleiro Insúa, L.A.; Petrelli, H.A. 2010. Control estructural de las mineralizaciones de fluorita del Batolito Cerro Áspero, Sierras Pampeanas de Córdoba. Revista de la Asociación Geológica Argentina 67 (4): 507-520.

Costa, C.H.; Giaccardi, A.D.; González Díaz, E.F. 1999. Palaeolandsurfaces and neotectonic analysis in the Southern Sierras Pampeanas. In Uplift, erosion and stability: Perspectives on long-term landscape development (Smith, B.J.; Whalley, W.B.; Warke, P.A.; editors). Anthony Rowe Ltd. Geological Society Special Publication 162: 229-238. Londres.

Cowardin, L.; Carter, V.; Golet, F.; LaRoe, T. 1979. Classification of Wetlands and Deepwater Habitats of the United States. U.S. Fish and Wildlife Service, FWS/OBS-79/31. Washington D.C.

Díaz, S.; Cabido, M. 1997. Plant functional types and ecosystem function in relation to global change. Journal of Vegetation Science 8: 463-474.

Degiovanni, S.; Doffo, N.; Villegas, M. 2009. Rejuvenecimiento de la red de drenaje del sur de Córdoba (Argentina) como consecuencia del cambio climático durante la última centuria. In Geomorfología y Cambio Climático (Sayago, J.M.; Collantes, M.M.; editores). Magna Ediciones: 79-95. San Miguel de Tucumán.

Doffo, N.; Degiovanni, S.; Villegas, M. 2010. Evolución de redes de drenaje en áreas de llanura. El caso del arroyo Las Lajas, Córdoba, Argentina. Cuadernos del CURIHAM 16: 49-57.

Espizua, L. 2005. Holocene glacier chronology of Valenzuela Valley, Mendoza Andes, Argentina. The Holocene 15: 1079-1085.

Faegri, K.; Iversen, J. 1989. Textbook of pollen analysis, $4^{\text {th }}$ Edition. John Wiley and Sons: 314 p. Chichester.

Fagiano, M.R. 2007. Geología y petrología del basamento cristalino de Las Albahacas, Sur de la Sierra de Comechingones, Córdoba. Tesis Doctoral (Inédito), Universidad Nacional de Río Cuarto, Departamento de Geología: 375 p.

Folk, R.L.; Andrews, P.B.; Lewis, D.W. 1970. Detrital sedimentary rock classification and nomenclature for use in New Zealand. New Zealand Journal of Geology and Geophysics 13: 937-968.

Folk, R.L.; Ward, W.C. 1957. Brazos River bar-A study in the significance of grain-size parameters. Journal of Sedimentary Petrology 27 (1): 3-27.

Forman, S.L.; Tripaldi, A.; Ciccioli, P.L. 2014. Eolian sand sheet deposition in the San Luis paleodune field, western Argentina as an indicator of a semi-arid environment through the Holocene. Palaeogeography, Palaeoclimatology and Palaeoecology 411: 122-135.

Gaitán, J.; Bran, D.; Raffo, F.; Ayesa, J. 2015. Evaluación y cartografía de mallines de las zonas de Loncopué y Chos Malal, provincia del Neuquén. Comunicación técnica, No. 131, área recursos naturales relevamiento integrado. Instituto Nacional de Tecnología Agropecuaria (INTA): $41 \mathrm{p}$.

Gandullo, R.; Schmid, P. 2001. Análisis ecológico de mallines del Parque Provincial Copahue, Neuquén, Argentina. Agro sur 29 (2): 83-99.

Gari, N.; Carigliano, M.C. 2004. La estructura del perifiton y de la deriva algal en arroyos serranos. Limnetica 23 (1-2): 11-24.

Gassmann, M.I.; Pérez, C.F. 2006. Trajectories associated to regional and extra-regional pollen transport in the southeast of Buenos Aires province, Mar del Plata (Argentina). International Journal of Biometeorology 50: 280-291.

Germanoski, D.; Miller, J.R.; Lord, M.L. 2011. Controls on Meadow Distribution and Characteristics. In Great Basin Riparian Ecosystems: ecology, management, 
and restoration (Chambers, J.C.; Miller, J.R.; editors). Island Press: 11-23. Washington.

Giorgis, M.A.; Cingolani, A.M.; Cabido, M. 2013. El efecto del fuego y las características topográficas sobre la vegetación y las propiedades del suelo en la zona de transición entre bosques y pastizales de las sierras de Córdoba, Argentina. Boletín de la Sociedad Argentina de Botánica 48: 493-513.

González, J. 2002. Sistemas de información geográfica y modelos hidrológicos: articulación para el estudio de una cuenca serrana en Córdoba (Argentina). Tesis de Maestría (Inédito), Universidad del Comahue: $212 \mathrm{p}$.

Gorgas, J.A.; Tassile, J.; Jarsún, B.; Zamora, E.; Bosnero, E.; Lovera, E.; Ravelo, A.; Carnero, M.; Bustos, V.; Pappalardo, J.; Petropulo, G.; Rossetti, E.; Ledesma, M. 2003. Los recursos naturales de la Provincia de Córdoba: Los suelos. Agencia Córdoba D.A.C. y T.S.E.M. Dirección de Ambiente, Instituto Nacional de Tecnología Agropecuaria (INTA). Manfredi.

Grimm, E. 2004. Tilia Software 2.0.4, Illinois State Museum. Research and Collection Center, Springfield, Illinois.

Hassan, G.; Espinosa, M.A.; Isla, F.I. 2004. Análisis paleoambiental de una secuencia del Holoceno Tardío del Arroyo Claromecó (provincia de Buenos Aires, Argentina) basado en diatomeas. Ameghiniana 41: 161-170.

Heiri, O.; Lotter, A.F.; Lemcke, G. 2001. Loss on ignition as a method for estimating organic and carbonate content in sediments: reproducibility and comparability of results. Journal of Paleolimnology 25: 101-110.

Heusser, J.C. 1971. Pollen and Spores of Chile. Modern Types of the Pteridophyta, Gymnospermae, and Angiospermae. The University of Arizona Press: 167 p. Tucson.

Hogg, A.G.; Hua, Q.; Blackwell, P.G.; Buck, C.E.; Guilderson, T.P.; Heaton, T.J.; Niu, M.; Palmer, J.G.; Reimer, P.J.; Reimer, R.W.; Turney, C.S.M.; Zimmerman. S.R.H. 2013. Radiocarbon 55 (4): 1889-1903. doi: 10.2458/azu_js_rc.55.16783.

Hudson, A.M.; Olsen, J.W.; Quade, J.; Lei, G.; Huth, T.E.; Zhang, H. 2016. A regional record of expanded Holocene wetlands and prehistoric human occupation from paleowetland deposits of the western Yarlung Tsangpo valley, southern Tibetan Plateau. Quaternary Research 86 (1): 13-33.

Iriondo, M.H.; Orellana, J.; Neiff, J. 1974. Sobre el concepto de mallín cordillerano. Revista de la Asociación de Ciencias Naturales del Litoral 5: 45-52.
Jordan, T.E.; Zeitler, P.; Ramos, V.; Gleadow, A.J.W. 1989. Thermochronometric data on the development of the basement peneplain in the Sierras Pampeanas, Argentina. Journal of South American Earth Sciences 2 (3): 207-222.

Krammer, K.; Lange Bertalot, H. 1986. SüBwasserflora von Mitteleuropa. Bacillariophyceae 2. Naviculaceae. 2/1 . G. Fischer. Verlag, Jena: 875 p. New York.

Krammer, K.; Lange Bertalot, H. 1988. SüBwasserflora von Mitteleuropa. Bacillariophyceae 2. Bacillariaceae, Epithemiaceae, Surirellaceae 2/2. G. Fischer. Verlag Stuttgart: 596 p. New York..

Krammer, K.; Lange Bertalot, H. 1991. SüBwasserflora von Mitteleuropa. Bacillariophyceae 3. Centrales, Fragilariaceae, Eunotiaceae 2/3. G. Fischer. Verlag Stuttgart: 576 p. New York.

Krammer, K.; Lange Bertalot, H. 2000. Bacillariophyceae. 3. Teil: Centrales, Fragilariaceae, Eunotiaceae. In Süßwasserflora von Mitteleuropa, Bd. 2/3 ed. 2. (Ettl, H.; Gerloff, J.; Heynig, H.; Mollenhauer, D.; editors). Stuttgart, G. Fischer. Verlag, Jena.

Krammer, K.; Lange Bertalot, H. 2004. Bacillariophyceae. 4. Teil: Achnanthaceae Kritische Ergänzungenzu Navicula (Lineolatae) und Gomphonema. In Süsswasserflora von Mitteleuropa (Ettl, H.; Gerloff, J.; Heynig, H.; Mollenhauer, D.; editors).

Krapovickas, J.M.; Tauber, A.A. 2016. Estratigrafía de las áreas cumbrales de las Sierras Pampeanas de Córdoba: geocronología, modelo regional, paleoambiente y paleoclima en una región poco conocida de Argentina. Revista Mexicana de Ciencias Geológicas 33 (1): 105-121.

Krapovickas, J.M.; Tauber, A.A.; Haro, A. 2017. Quaternary biostratigraphy and biogeography of mountain region of Córdoba, Argentina. Geobios 50: 211-236.

Kröhling, D.; Carignano, C. 2014. La estratigrafía de los depósitos sedimentarios cuaternarios. In Relatorio del Congreso Geológico Argentino, No. 19. Geología y Recursos Naturales de la Provincia de Córdoba. (Martino, R.; Guereschi, A.; editores). ALSAPEMA S.A.: 673-724. Córdoba.

Kusber, W.H.; Jahn, R. 2002. Annotated list of diatom names by Horst Lange-Bertalot and co-workers. Versión 2.0: 62p. Disponible en http://www.algaterra. org/Names_Versión 2_0 Draft.pdf (Última visita 05/09/2018).

Lange Bertalot, H. 2001. Diatoms of Europe. Diatoms of the European Inland Waters and Comparable Habitats. Vol. 2. Navicula sensu stricto, 10 genera separated 
from Navicula sensu lato, Frustulia. Gantner Verlag K.G.: 526 p. Alemania.

Liutkus, C.M.; Ashley, G.M. 2003. Facies model of a semiarid freshwater wetland, Olduvai Gorge, Tanzania. Journal of Sedimentary Research 73: 691-705.

Lord, M.; Jewett, D.; Miller, J.R.; Germanoski, D.; Chambers, J.C. 2011. Hydrologic processes influencing meadow ecosystems. In Great Basin Riparian Ecosystems: ecology, management and restoration (Chambers, J.C.; Miller, J.R.; editors). Island Press: 44-67. Washington.

Luque, M.E.; Martínez de Fabricius, A.L. 2003. Distribución temporal del fitoplancton y epiliton en el río Piedra Blanca (Córdoba, Argentina). Limnetica 22 (3-4): 19-34.

Luti, R.; Bertrán de Solís, M.A.; Galera, M.F.; Müller de Ferreira, N.; Berzal, M.; Nores, M.; Herrera, M.A.; Barrera, J.C. 1979. Vegetación. In Geografía Física de la provincia de Córdoba (Vázquez, J.; Miatello, R.; Roque, M.; editores). BOLDT: 297-368. Buenos Aires.

Magnante, L.; Degiovanni, S.; Doffo, N. 2014. Variaciones Morfológicas y Morfodinámicas del arroyo El Cano (Córdoba), en la última centuria. Causas e implicancias ambientales. Revista de la Asociación Geológica Argentina 71 (1): 56-68.

Maldonado, M.; Rozas, E. 2008. Clima y Paleoambientes durante el Cuaternario Tardío en la Región de Atacama. In Libro Rojo de la Flora Nativa y de los Sitios Prioritarios para su Conservación: Región de Atacama (Squeo, F.A.; Arancio, G; Gutierrez, J.R.; editores). Ediciones Universidad de La Serena: 293-304. La Serena.

Mancini, M.V. 2009. Holocene vegetation and climate changes from a peat record of the forest-steppe ecotone, Southwest of Patagonia (Argentina). Quaternary Science Reviews 28: 1490-1497.

Mancini, M.V.; Paez, M.M.; Prieto, A.R.; Stutz, S.; Tonello, M.; Vilanova, I. 2005. Mid-Holocene climatic variability reconstruction from pollen records $\left(32^{\circ}\right.$ $52^{\circ} \mathrm{S}$, Argentina). Quaternary International 132: 47-59.

Manzano, M.; Borja, F.; Montes, C. 2002. Metodología de tipificación hidrológica de humedales españoles. Boletín ITGME 113 (3): 313-330.

Manzur, A. 1997. Dinámicas evolutivas de suelos en Atum Pampa, Sierras Pampeanas, Córdoba, Argentina. Multequina 6: 67-83.

Markgraf, V. 1983. Late and post-glacial vegetational and paleoclimatic changes in subantarctic, temperate and arid environments in Argentina. Palynology 7: 43-70.

Markgraf, V.; Bianchi, M.M. 1999. Paleoenvironmental changes during the last 17,000 years in the western Patagonia: Mallín Aguado, Province of Neuquén, Argentina. Geographische Schriften 19: 175-193.
Markgraf, V.; D’Antoni, H.L. 1978. Pollen Flora of Argentina. The University of Arizona Press: 201 p. Tucson.

Martínez, G.A.; Arana, M.D.; Oggero, A.J.; Natale, E.S. 2016. Biogeographical relationships and new regionalization of high-altitude grasslands and woodlands of the central Pampean Ranges (Argentina), based on vascular plants and vertebrates. Australian Systematic Botany 29: 473-488.

Mazzoni, E.; Rabassa, J. 2013. Types and internal hydrogeomorphologic variability of mallines (wet-meadows) of Patagonia: Emphasis on volcanic plateaus. Journal of South American Earth Sciences 46: 70-182.

Méndez, E. 2007. La vegetación de los Altos Andes II. Las Vegas del flanco oriental del Cordón del Plata (Mendoza, Argentina). Boletín de la Sociedad Argentina de Botánica 42 (3-4): 273-294.

Metzeltin, D.; Lange-Bertalot, H.; García Rodríguez, F. 2005. Diatoms of Uruguay. Compared with other taxa from South America and elsewhere. A.R.G. Gantner: 736 p.

Miller, J.R.; Lord, M.L.; Villarroel, L.F.; Germanoski, D.; Chambers, J.C. 2012. Structural organization of process zones in upland watersheds of central Nevada and its influence on basin connectivity, dynamics, and wet meadow complexes. Geomorphology (139-140): 384-402.

Ministerio de Ambiente y Desarrollo Sustentable. 2016. Estadística de incendios forestales 2015. 142p. Disponible en: http://ambiente.gob.ar/wp-content/ uploads/INCENDIOS-FORESTALES-2015-1-1.pdf (Última visita 01/05/2018).

Oggero, A.J.; Arana, M.D. 2012. Inventario de las plantas vasculares del sur de la zona serrana de Córdoba, Argentina. Hoehnea 39 (2): 171-199.

Owen, R.B.; Renaut, R.W.; Hover, V.C.; Ashley, G.M.; Muasya, A.M. 2004.Swamps, springs and diatoms: wetlands of the semi-arid Bogoria-Baringo Rift, Kenya. Hydrobiologia 518: 59-78.

Oxman, B.; Tchilinguirian, P.; Yacobaccio, H.D.; Lupo, L.C. 2015. Nuevos análisis paleoambientales y sus implicancias arqueológicas durante la Pequeña Edad de Hielo en la Puna. Estudios sociales del NOA16: 13-38.

Passy, S.I. 2007. Diatom ecological guilds display distinct and predictable behaviour along nutrient and disturbance gradients in running waters. Aquatic Botany 86: 171-178.

Pigati, J.S.; Rech, J.A.; Nekola, J.C. 2010. Radiocarbon dating of small terrestrial gastropodsin North America. Quaternary Geochronology 5: 519-532. 
Pigati, J.S.; Rech, J.A.; Quade, J.; Bright, J. 2014. Desert wetlands in the geologic record. Earth-Science Reviews 132: 67-81.

Pinotti, L.; Coniglio, J.; Esparza, A.; D'Eramo, F.; Llambías, E. 2002. Nearly circular plutons emplaced by stoping at shallow crustal levels, Cerro Aspero batholiths, Sierras Pampeanas de Córdoba, Argentina. Journal of South American Earth Sciences 15: 251-265.

Pinotti, L.; Coniglio, J.E.; D’Eramo, F.; Demartis, M.; Otamendi, J.E.; Fagiano, M.R.; Zambroni, N.E. 2014. El magmatismo devónico: Geología del batolito de Cerro Aspero. In Relatorio Congreso Argentino de Geología, No. 19. Geología y Recursos Naturales de la Provincia de Córdoba (Martino, R.; Guereschi, A.; editores). ALSAPEMA S.A.: 255-276. Córdoba.

Piovano, E.L.; Ariztegui, D.; Córdoba, F.; Cioccale, M.; Sylvestre, F. 2009. Hydrological variability in South America below the Tropic of Capricorn (Pampas and Patagonia, Argentina) during the last $13.0 \mathrm{ka}$. In (F. Vimeux et al.; editors), Past Climate Variability in South America and Surrounding Regions, Developments in Paleoenvironmental Research 14: 323-351.

Quade, J.; Mifflin, M.D.; Pratt,W.L.; McCoy, W.D.; Burckle, L. 1995. Fossil spring deposits in the southern Great Basin and their implications for changes in watertable levels near Yucca Mountain, Nevada, during Quaternary time. Geological Society of America Bulletin 107 (2): 213-230.

Rabassa, J. 2008. Late Cenozoic glaciations in Patagonia and Tierra del Fuego. In The Late Cenozoic of Patagonia and Tierra del Fuego (Rabassa, J.; editor). Developments in Quaternary Science 11: 151-204.

Rabassa, J.; Carignano, C.; Cioccale, M. 2010. Gondwana Paleosurfaces in Argentina: An Introduction. Geociências 29 (4): 439-466.

Raffaele, E. 1999. Mallines: aspectos generales y problemas particulares. In Tópicos sobre humedales subtropicales y templados de Sudamérica (Malvárez, A.I.; editor). Oficina Regional de Ciencia y Tecnología de la UNESCO para América Latina y el Caribe: 27-33. Montevideo.

Rey Ripoll, M. 2008. Perfil geológico-estructural de la faja de cizalla Guacha Corral, Sa. de Comechingones en $\operatorname{los} 32^{\circ} 45^{\prime} \mathrm{S}$. Evaluación del potencial metalogenético. Tesis de Licenciatura (Inédito). Universidad Nacional de Río Cuarto, Departamento de Geología: $87 \mathrm{p}$.

Roig, C; Roig, F.A. 2004. Consideraciones generales. In Los Turbales de la Patagonia. Bases para su inventario y la conservación de su biodiversidad (Blanco, D.E.; de la Balze, B.M.; editores). Wetlands International Publication 19: 5-21.

Sanabria, J.; Tauber, A.; Argüello, G.; Morrás, H.; Moretti, L.; Krapovickas, J.; Rouzaut, S.; Mansilla, L.; Zahn, E. 2014. Paleosuelos del Holoceno en el área de Los Gigantes, Sierra Grande de Córdoba, Argentina. In Congreso Geológico Argentino, No. 19. Actas: $1075-$ 1076. Córdoba.

Scopel, A.L.; Cantero, J.C.; Silva, M.P. 2017. Región Humedales Valliserranos. Subregión Arroyos y mallines de las sierras centrales. In Regiones de humedales de la Argentina (Benzaquén, L.; Blanco, D.; Bo, R.; Kandus, P.; Lingua, G.; Minotti, P.; Quintana, R.; editores). Ministerio de Ambiente y Desarrollo Sustentable, Fundación Humedales/Wetlands International, Universidad Nacional de San Martín y Universidad de Buenos Aires: 173-183. Buenos Aires.

Silva, L.C.R.; Giorgis, M.A.; Anand, M.; Erico, L.; Pérez-Harguindeguy, N.; Falczuk, V.; Tieszen, L.L.; Cabido, M. 2011. Evidence of shift in C4 species range in central Argentina during the late Holocene. Plant Soil 349: 261-279.

Solomina, O.N.; Bradley, R.S.; Hodgson, D.A.; Ivy-Ochs, S.; Jomelli, V.; Mackintosh, A.N.; Nesje, A.; Owen, L-A.; Wanner, H.; Wiles, G.C.; Young, N.E. 2015. Holocene glacier fluctuations. Quaternary Science Reviews 111: 9-34.

Suárez, S.A. 1993. Mapeo fisionómico-estructural de la vegetación natural del Departamento Río Cuarto. III Achiras y Las Cañitas. Beca de Iniciación: informe final. Universidad Nacional de Río Cuarto, Departamento de Ciencias Naturales.

Suárez, S.; Vischi, N. 1997. Caracterización fisonómicoestructural de vegetación serrana (Alpa CorralCórdoba-Argentina). Multequina 6: 21-32.

Stillwater Sciences. 2012. A guide for restoring functionality to mountain meadows of the Sierra Nevada. Technical memorandum. Prepared by Stillwater Sciences, Berkeley, California for American Rivers: 74 p. Nevada City.

Strasser, E.; Gásquez, J.A.; Fernández Turiel, J.L.; Marchevsky, E.; Osterrieth, M.; Prado, J.L.; Chiesa, J.; Perino, E. 2014. Inferencias paleoedafoclimáticas en el registro de sedimentación loéssica finipleistocénicaholocénica en el piedemonte y pampa de altura de la Sierra de San Luis (Argentina). In Procesos geoquímicos superficiales en Iberoamérica. (Marcovecchio, J.E.; Botté, S.E.; Freija, R.H.; editores). Nueva Graficesa, S.L., Salamanca: 279-302. Bahía Blanca. 
Stuiver, M.; Reimer, P.J.; Reimer, R.W. 2018. CALIB 7.1.0 program.

Torretta, J.P.; Basilio, A.M. 2009. Dispersión polínica y éxito reproductivo de cuatro especies arbóreas de un bosque xerófito de Argentina. Revista de Biología Tropical 57 (1-2): 283-292.

Tooth, S.; Mc Carthy, T.S. 2007. Wetlands in drylands: geomorphological and sedimentological characteristics, with emphasis on examples from southern Africa. Progress in Physical Geography 31 (1): $3-41$.

Utrilla, V.; Brizuela, M.; Cibils, A. 2005. Riparian habitats (mallines) of Patagonia. A key grazing resource for sustainable sheep-farming operations. Outlook on Agriculture 34 (1): 55-59.

Vázquez, M.; Diez, P.; Grima, D. 2013. Relación suelo. Humedad y composición fisonómica florística del mallín La Carlota. Contribuciones Científicas GÆA 25: 197-209.
Vischi, N.; Oggero, A.; Correa, A.L.; Suárez, S. 1999. Comunidades vegetales del Bosque Serrano y su asociación con factores edáficos (Sierra de Comechingones, Córdoba). Boletín de la Sociedad Argentina de Botánica 34 (1-2): 107-112.

Wu, N.; Tang, T.; Zhou, S.C.; Jia, X.H.; Li, D.F.; Liu, R.Q.; Cai, Q.H. 2009. Changes in benthic algal communitiesfollowing construction of a run-of-river dam. Journal of the North American Benthological Society 28: 69-79.

Zech, R.; Kull, C.; Veit, H. 2006. Late Quaternary glacial history in the Encierro Valley, northern Chile $\left(29^{\circ} \mathrm{S}\right)$, deduced from ${ }^{10} \mathrm{Be}$ surface exposure dating. Palaeogeography, Palaeoclimatology, Palaeoecology 234: 2-4.

Zech, R.; Kull, Ch.; Kubik, P.W.; Veit, H. 2007. Exposure dating of Late Glacial and pre-LGM moraines in the Cordon de Dona Rosa, Northern/Central Chile $\left(\sim 31^{\circ} \mathrm{S}\right)$. Climate of the Past 3: 1-14.

Manuscrito recibido: Diciembre 22, 2017; revisado/aceptado: Marzo 4, 2019; disponible en línea: Septiembre 30, 2019. 